\title{
A roadmap to immunotherapy: lesson from the hallmarks and signaling pathways of cancer
}

\author{
Afshin Derakhshani ${ }^{1,2 \dagger}$, Zeinab Rostami ${ }^{3 \dagger}$, Hossein Safarpour ${ }^{4 \dagger}$, Sina Taefehshokr ${ }^{1}$, Neda Jalili \\ Tabrizi', Mahdi Abdoli Shadbad1, Omid Kooshkaki ${ }^{3}$, Reza Vaezi Astamal1, Antonella \\ Argentiero ${ }^{2}$, Pankaj Kumar Singh ${ }^{5}$, Nima Taefehshokr ${ }^{6}$, Nazila Alizadeh', Nicola Silvestris ${ }^{2,7}$, \\ Behzad Baradaran ${ }^{1,8^{*}}$
}

1 Immunology Research Center, Tabriz University of Medical Sciences, Tabriz, Iran; afshin.derakhshani94@gmail.com (AD), sinataefehshokr@gmail.com (ST), jalili.t.neda@gmail.com (NJT), abdoli.med99@gmail.com (MAS), rezavaezi72@gmail.com (RVA), alizadeh_imm@yahoo.com (NA)

2 IRCCS Istituto Tumori “Giovanni Paolo II" of Bari, Bari, Italy; a.argentiero@oncologico.bari.it (AA), n.silvestris@oncologico.bari.it (NS)

3 Student research committee, Birjand University of medical sciences, Birjand, Iran; zeinabrostamy73@gmail.com (ZR), omidkoshki@gmail.com (OK)

4 Cellular \& Molecular Research Center, Birjand University of Medical Sciences, Birjand, Iran; safarpour701@yahoo.com (HS)

5 Principal Research Technologist, Department of Radiation Oncology, Mayo Clinic, FL, USA; Singh.pankaj@mayo.edu (PKS)

6 Department of Microbiology and Immunology, Center for Human Immunology, The University of Western Ontario, London, ON, Canada; n.taefehshokr@gmail.com (NT)

7 Department of Biomedical Sciences and Human Oncology, University of Bari "Aldo Moro", Bari, Italy; n.silvestris@oncologico.bari.it (NS)

8 Department of Immunology, Faculty of Medicine, Tabriz University of Medical Sciences, Tabriz, Iran; baradaranb@tbzmed.ac.ir (BB)

† These authors contributed equally to this manuscript

* Correspondence: email: baradaranb@tbzmed.ac.ir; Tel.: +98 413 3371440, Fax: +98 4133371311 (BB).

Email: a.argentiero@oncologico.bari.it; Tel.: +39 0805555426 (AA).

\begin{abstract}
Cancer is the second leading cause of death worldwide. It is theorized that underlying genetic and epigenetic changes enable cells to proliferate out of control by escaping regulatory mechanisms. Although traditional molecular profiling techniques, i.e., bulk sequencing, can identify common mutations and gene expression patterns in cancer cells, they cannot detect tumor heterogeneity. However, single-cell technology has provided an ample opportunity to overcome this difficulty. Since this technology allows us to detect the heterogeneous properties of all cancer cells, this can further our knowledge of the signaling pathways in cancer cells. Indeed, single-cell transcriptomics technology has paved the road for identifying novel biomarkers and signaling pathways, which can serve as targets. This study aims to review the current knowledge about pathways involved in developing cancer cells and shed light on single-cell studies as promising therapeutic approaches.
\end{abstract}

Keywords: cell signaling; signaling pathways; single-cell sequencing; immunotherapy; hallmarks cancer; cancer

\section{Introduction}

The biological deconvolution of cancer pioneered major breakthroughs for the clinicians and their patients, providing revolutionary diagnostic and therapeutic windows in oncology [1]. The 
immunotherapy next generation rightfully represents the state-of-the-art translational application of decades of pre-clinical and clinical investigation. Nonetheless, the prognosis for subjects suffering from cancer remains sober, due to the disease complexity and drug resistance. Indeed, it has been characterized that genetic modifications, epigenetic modifications, or both are potential drivers of malignancy [1,2]. Carcinogenesis is the result of an increase in cell proliferation, resistance to apoptosis, genetic instability, angiogenesis, metabolic modifications, and cell migration capability $[3,4]$. Most of these changes are caused by signaling components that are involved in dysregulation of cell signaling pathways [5]. Over the past decades, several experiments have described various signaling components that help build a molecular structure for a number of signal transduction pathways [6]. Intercellular heterogeneity stands a main portion of intratumor heterogeneity, leading to development of drug resistance, tumor reoccurrence as well as metastasis [7,8]. Intratumor heterogeneity in various cascades can dis-regulate cancer biology, prognosis, and therapy $[9,10]$. For example, particular RNA variants are participated in biological function including cell surface signaling, cell adhesion, microtubule organization and stabilization in different type of metastatic cancer. Further, cells with a definite type of RNA variants become drug-resistant after chemotherapy. So, it is needed to perform more precise analysis of tumor cells. Advances in whole genome amplification and next-generation sequencing technologies have allowed single-cell genomic studies, and these approaches are now starting to be used in individual cancer cells to diagnose genomic lesions. Considering the importance of characterizing tumor heterogenicity for cancer therapy, previous approaches, have struggled to address genomic variations in diverse cell mixtures [11]. Our understanding of cancer evolution, tumor heterogeneity, and the tumor microenvironment has been revolutionized with the introduction of single cell sequencing technology and applications of cancer science [12]. In this review, various known cancer pathways are comprehensively explained to identify ways through which cancer cells evade the immune system and the role of related genes. Additionally, application of single cell sequencing in clarifying of pathways of drug resistance and immunotherapy-based treatment of cancer are discussed.

\section{Tumorigenesis and signaling pathways}

Overexpression of oncogenes and oncoproteins may promote abnormal signals leading to tumorigenesis [13]. Studies have shown that mutations via the activation of proto-oncogenes and the inactivation of tumor suppressor genes can contribute to tumorigenesis $[14,15]$. To shape a tumor, cells need to obtain some features, e.g., the inhibition of apoptosis and the development of angiogenesis, proliferation, and invasion [3,16,17]. Biological functions are preserved by one or more groups of genes and proteins that cooperate in signaling pathways and can lead to the proliferation and survival of cancer cells [18]. Genetic alterations in cancer cells regulate signaling pathways that can also lead to tumorigenesis. Oncogenic mutations can affect proteins involved in several signaling pathways, such as Hedgehog (Hh), Wnt, and Hippo. These proteins are commonly activated in many physiological responses and in cancer development and invasion [19-22]. Cross-talks between Wnt, Hippo, and Hh pathways, which have been observed at different levels, are crucial in cancer pathology [23-25]. Several studies indicated that the combination of Wnt inhibitors and chemotherapy improved tumor reduction in several solid tumors and affected the immune microenvironment [26-28]. Oncogenic mutations may affect the downstream nuclear targets of signaling pathways, such as chromatin remodelers (e.g., Enhancer of zeste homolog 2 (EZH2)), cell cycle effectors (e.g., cyclins), and transcription factors (e.g., Nuclear factor-kappa B (NF- $\kappa \mathrm{B})$ and Myc) [1]. Additionally, somatic mutations and genomic deletions may inactivate tumor suppressors. The tumor suppressor gene p53, also known as the guardian of the genome, is mutated in about half of human cancers and regulates cell proliferation and stress signals such as DNA response and apoptosis [29-31]. The p16 gene (CDKN2A), another tumor suppressor gene, inhibits cyclin-dependent kinase D. Most of the tumor suppressors function as a negative cytoplasmic regulator, such as adenomatous polyposis coli protein (APC) and tensin homolog (PTEN). APC is a negative modulator of the Wnt pathway, and PTEN is a negative modulator of the PI3K-AKT pathway $[32,33]$. The stimulation of the oncogene pathway could also lead to irreversible 
cell cycle arrest in the G1 phase, known as senescence [34-36]. Receptor tyrosine kinase (RTK)-Ras-extracellular signal-regulated kinase (ERK) signaling pathway is another dysregulated pathway with the highest median frequency of changes among all types of cancers [37,38]. Abnormal RTK activation in cancer is mediated by four major mechanisms: gain of function mutations, genomic increase, chromosomal rearrangements, and autocrine activation [39]. Dysregulation of this pathway may affect several cancers such as melanoma, the genomic-stable subtype of colorectal cancer, HER2-enriched breast cancer, pancreatic cancer, IDH1-wild-type glioma, lung adenocarcinoma, and thyroid carcinoma [1]. Furthermore, some types of tumors, such as lung cancer, EBV-positive esophagogastric cancer, squamous cell carcinoma, and non-hypermutated uterine cancer showed high rates of alterations in the PI3K pathway. The Wnt signaling pathway is another altered pathway in colorectal cancer. In some pathways, several genes developed the genetic alterations (e.g., cell cycle, PI3K), whereas, in others, only limited genes were involved in the modifications (Wnt, Myc, and NRF2) [1]. Aberrations in the PI3K pathway are activating events in phosphatidylinositol-4,5-bisphosphate 3-kinase catalytic subunit alpha (PIK3CA) and are inactivating events in phosphoinositide-3-Kinase Regulatory Subunit 1 (PIK3R1) or PTEN, with the gene alterations occurring in breast cancer, head and neck cancer, gynecological and gastrointestinal tumors [40]. Pancreatic and gastrointestinal cancers have the highest alteration rate in the TGF $\beta$ pathway, whereas renal and brain cancers have almost no genetic alterations in the pathway [41]. Studies demonstrate that ovarian cancer and breast cancer cells highly depend on Myc for maintaining their oncogenic growth, which marks Myc as a therapeutic target for these difficult-to-treat malignancies [42]. The role of signal transduction in cancer cell-associated processes is discussed in the next section.

\subsection{Cell proliferation}

Proliferation is a major part of cancer development and progression. Modified expression and activation of cell cycle-dependent proteins lead to cell proliferation. [43]. Abnormal proliferation is a hallmark of most cancers and involves the modulation of various signaling pathways. There are several different genes and proteins which play critical roles in the signaling pathways. For example, Notch proteins are a family of type I transmembrane receptors which play a significant role in human cancer pathogenesis [44]. Notch1 signaling mediated hypoxia/HIF-1 $\alpha$ can stimulate cell proliferation in T-cell acute lymphoblastic leukemia (T-ALL) [45]. After activation of Notch signaling, a ligand binds to a Notch receptor, as in the case of Jagged-2 (JAG2) binding to Notch2 and upregulating cell proliferation [46]. Notch3 is also associated with tumor cell proliferation [47]. Studies reported that the Hairy and enhancer of split 1 (Hes1) plays a critical role in regulating differentiation and proliferation of neuronal, endocrine, and T-lymphocyte progenitors during development $[48,49]$. The hedgehog $(\mathrm{Hh})$ signaling pathway through glioma-associated oncogenes (GLI2) may increase tumor proliferation, suggesting that inactivation of the Hh pathway could significantly reduce the proliferation of SMMC-7721 cell lines in hepatocellular carcinoma (HCC) [50-52]. Activation of the PI3K/Akt pathway via the binding of mechanistic target rapamycin complex I (mTORC1) controls cell growth and suppresses tuberous sclerosis complex1-2 (TSC1TSC2) GAP activity towards Rheb (now GTP bound), leading to mTORC1 activation [53]. AKT also phosphorylates the glycogen synthase kinase 3 (GSK3), cyclin D, and Myc and inhibits catalytic activity [54,55]. Moreover, AKT dysregulates several inhibitors of the cell cycle such as p21 (CIP1) and cyclin-dependent kinase inhibitor (CKI) p27 (KIP1), whereas phosphorylated AKT leads to 14-3-3 proteins sequestration in the cytoplasm. AKT, via phosphorylation of p21, prevents the formation of a complex proliferating nuclear cell antigen (PCNA) in order to suppress DNA replication, decrease p21 attachment to cyclin-dependent protein kinases 2/4 (CDK2/CDK4), and decrease the down regulatory function of p21 to CDK2 [56]. Moreover, AKT inhibits transcription factors of the forkhead box (FoxO), including RBL2 (retinoblastoma-like protein 2) and p27 [57], which stimulates the phosphorylation of mouse double minute 2 homolog (MDM2) and ubiquitin ligase promoting p53 degradation and triggering a main cell cycle brake [58]. AKT could also control multiple enzymes engaged in the G2/M transformation later in the cell cycle [59]. In some cases, consequent inhibition and phosphorylation of GSK3 through AKT can end to nuclear translocation 
and stabilization of the Wnt target $\beta$-catenin [60,61]. $\beta$-catenin target genes control the proliferation of proteins such as cyclin D and Myc. Moreover, AKT can immediately phosphorylate $\beta$-catenin, which results in its separation from cadherin cell-cell adhesion complexes and improvement of the $\beta$-catenin pool and transcription function [62]. Several signaling pathways could promote cancer cell proliferation. For example, cytokine and RTK signaling activate signal transducer and activator of transcription 3 (STAT3) and NF- $\kappa$ B, thus activating the synthesis of Myc and cyclin D [63]. Several signals induce cyclin E in Estrogen signaling [32], which stimulates cell proliferation by activating the estrogen receptor alpha (ER $\alpha)$ subtype. ER $\alpha$ stimulates Myc, and cyclin D. Disruption of the $\mathrm{ER} \alpha$-ER $\beta$ balance or ER $\alpha$ mutations could dysregulate the above mechanism [64-67]. It is noted that both Ras-ERK and PI3K-AKT signaling improve signals from ERs and the androgen receptor (AR) [68,69]. The role of tumor suppressors is critical to inhibiting cellular growth and proliferative signals. Farthest downstream, pRB directly inhibits the protein transcription activity of E2F through phosphorylation of CDKs. The p53 gene blocks cell proliferation by inhibiting CDK activity and inducing CKIs in response to stress signals such as DNA damage. Thus, p53 mutations dysregulate cell proliferation under dangerous conditions that promote cancer. The CKIs directly inhibit CDKs and are inactivated via mutations in several cancers. A common example of this is p16. Upstream genes are pathway-specific tumor suppressors, such as APC and Ras-GAP NF1, which inactivate Wnt $/ \beta$-catenin signaling by enhancing GSK3 phosphorylation, and thus the destruction of $\beta$-catenin by ubiquitin. Tumor suppressor mutation removes a significant brake that allows the cells to proliferate bypassing signals that would usually restrict them. The Hippo signaling pathway plays a pivotal role in controlling proliferation contact inhibition [70] and in suppressing the transcriptional Yes-associated protein (YAP) coactivator acting as a major tumor suppressor system in many cancers [71]. Activation of the Ras/PI3K/ERK pathway induces c-Myc stabilization by suppressing ubiquitylation [55]. Myc stimulates cell proliferation by regulating various cell proliferation proteins, including CDKs, G1/S cyclins, and the cell cycle-driven E2F family transcriptional factors [72], as shown in Figure 1.

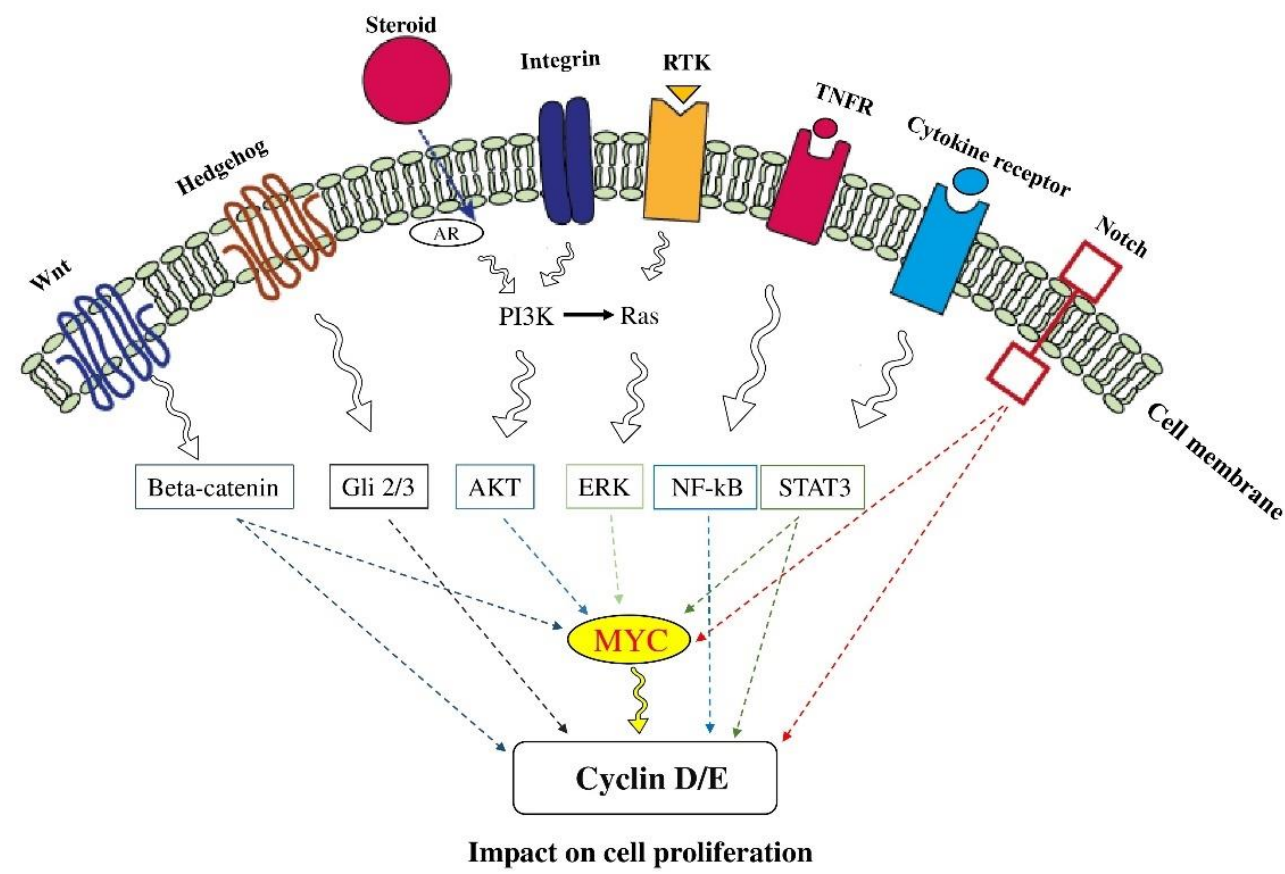

Figure 1. Signaling pathway and cell proliferation. Proliferation is an integral feature of the development and growth of cancers. It is expressed by the altered protein-related expression, cell cycle behavior, or both. Constitutive stimulation of many signal transduction pathways often promotes the development of cells. Abnormal cell proliferation is a hallmark of most cancers and involves the modulation of multiple signaling pathways (see main text for detail). 


\subsection{Cell survival}

Cell death serves as a homeostatic mechanism through which cells are regulated. However, mutations can significantly disable cell death signals for cancer cells. For instance, Notch signaling can encourage cell survival through communication between Jagged-2 (JAG2) ligand and receptor Notch2 in cancer [73]. Moreover, studies have indicated that the Ras-ERK and PI3K-AKT pathways control cell death in many aspects [74]. AKT itself interferes with the apoptotic signaling of mortality receptors at several stages. It phosphorylates forkhead-family transcription factors, including FoxO3A, which results in their cytoplasmic sequestration by 14-3-3 proteins. This stops the induction of pro-apoptotic B cell lymphoma 2 (Bcl2)-family member Bim, and death ligands (e.g., Fas ligand (FasL) and TRAIL). AKT phosphorylates and stimulates the $X$-linked inhibitor-of-apoptosis protein apoptosis inhibitor (XIAP) [75]. AKT also activates NF- $\kappa B$, which controls anti-apoptotic enzymes (Bcl2, BCLxl, and Mcl1) and the FLIP inhibitor intracellular mortality receptor [75]. ERK and AKT-regulated kinase RSK phosphorylate the Bcl2-family pro-apoptotic protein Bad, another target for 14-3-3 protein sequestration. Furthermore, the ubiquitylation and degradation of p53, initiated by AKT, represses apoptosis induced by p53 [58]. ERK phosphorylates Bim and the degradation targeting NF- $\kappa B$ inhibitor I $\kappa B \alpha$ [76]. Additionally, RSK phosphorylates the caspase-9 scaffolding protein APAF, which inhibits the capacity of cytochrome $\mathrm{c}$ to nucleate apoptosome development and stimulate downstream apoptosis-driven caspases [77] (Figure 2).

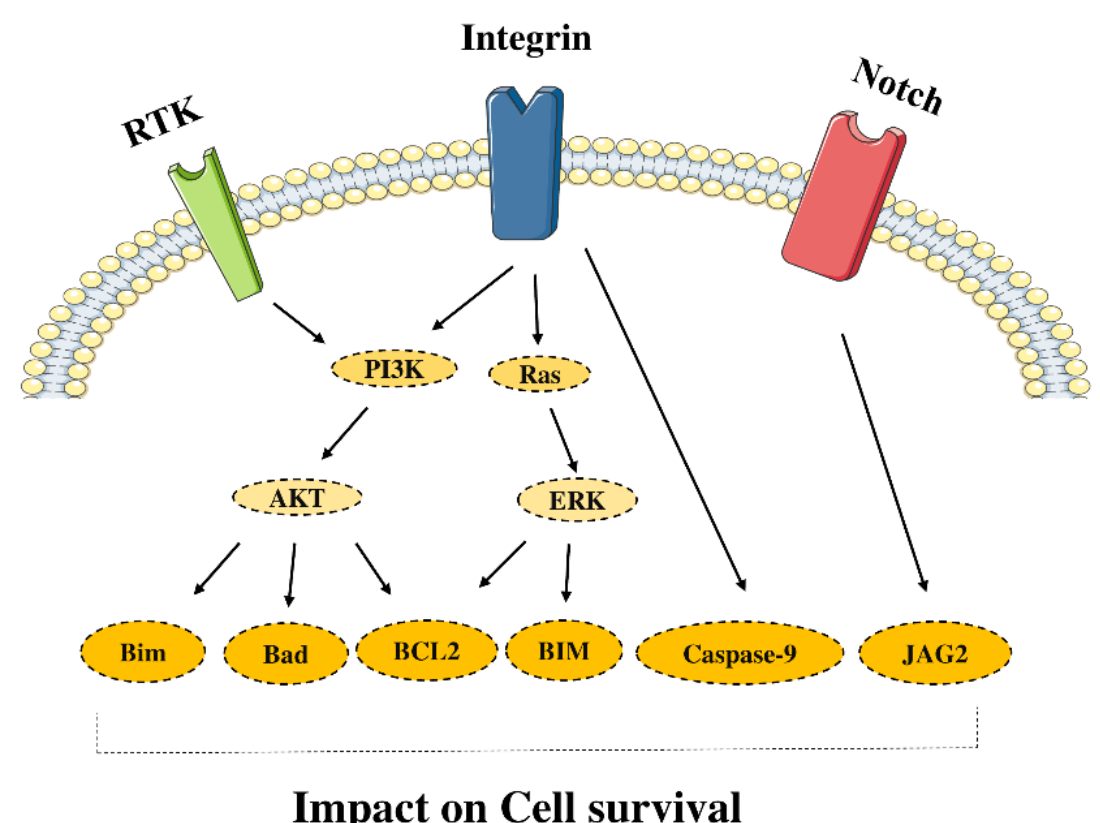

Figure 2. Signaling pathway and cell survival. Escape from cell death is one of the mechanisms to stave off anti-cancer treatments by cancer cells. The key players in preventing apoptosis are known collectively as survival proteins. There are other genes and pathways involved in cell survival, especially in cancer cells. The figure was produced using Servier Medical Art (http://smart.servier.com/).

\subsection{Cell metabolism}

Dysregulation of metabolism is a common phenomenon in cancer cells, such as mutations of isocitrate dehydrogenase 1 (IDH1) and 2 (IDH2) that can increase metabolites in cancer cells [78]. These mutations result in the production of 2-hydroxyglutarate (2HG), a metabolite not found at 
high levels in normal cells. The 2HG metabolite inhibits $\alpha$-ketoglutarate-dependent enzymes, including the DNA methylation-controlled TET family and histone demethylases of the Jumonji-C domain, and causes epigenetic dysregulation that can lead to tumorigenesis. Moreover, several parts of normal metabolic pathways can be controlled effectively and produce similar metabolic changes via suppressing tumor suppressors and oncogene activation. For instance, the PI3K-AKT pathway uses multiple substrates to support these changes in metabolism [79]. AKT regulates the transport of glucose and hexokinase, which promotes glycolysis, and results in producing the nucleotides and amino acids necessary for development [80]. Transport of glucose via AKT2 is important for glucose homeostasis [81]. AKT2 also regulates transcription, accumulation [82,83], and glucose transporter 1 (GLUT1) traffic (the main glucose transporter in most cells) [84]. The signaling of mTORC1 increases the synthesis of the hypoxia-inducible transcription factor (HIF1), which promotes lactate dehydrogenase (LDH-A) and glycolytic enzymes to upregulate glycolysis. It also triggers pyruvate dehydrogenase protein (PDK), which inhibits pyruvate dehydrogenase (PDH) in the mitochond rion, and as a result, decreases glycolysis flux into the Krebs cycle [85,86]. Additionally, mTORC1 regulates the absorption of amino acids by promoting their translocation from intracellular vesicles to plasma membranes. Sterol-response-element-binding protein 1 (SREBP) transcription factor, a regulator of lipid synthesis, is activated by mTORC1 in the Akt/mTORC1 pathway and results in increased lipid synthesis [87-89]. The loss of SREBP activity inhibits cancer cell growth and viability by uncoupling fatty acid synthesis from desaturation. ATP-citrate lyase (ACL), a target of AKT, is an important enzyme for the synthesis of fatty acids, cholesterol, isoprenoid, and the conversion of citric acid acetyl-CoA [90,91]. Ras-ERK signaling through Myc has important roles in glucose uptake, glycolysis, the pentose phosphate cycle, production of glutamine transporter, and glutaminase enzyme (GLS), which converts glutamine to glutamate [92] [93,94]. Despite the higher rate of glycolysis in cancer cells relative to non-cancer cells, many cancer cells generate an alternative and less active type of pyruvate kinase muscle isozyme (pyruvate kinase muscle isozyme M2, PKM2) [95]. PKM2 is a limiting glycolytic enzyme that catalyzes the final step in glycolysis, a key step in tumor metabolism and growth. PKM2 can be switched off through signaling pathways such as Ras-ERK and PI3K-AKT RTKs [96]. PKM2 could also enter the nucleus and contribute to gene expression. Consequently, cancer cells for glutathione and NADPH production can redirect the glycolytic flux into anabolic pathways. [97,98]. Tumor suppressors such as p53 regulate cell metabolism; therefore, loss of p53 may lead to cancer cell glycolytic phenotype, higher oxidative damage, and ROS levels. P53 often regulates glutaminase 2 (GLS2), a mitochondrial phosphate-activated glutaminase that catalyzes the hydrolysis of glutamine producing glutamate and ammonia. [99]. GLS2 has tumor suppressant properties and limits malignancy. P53 also regulates the mevalonate pathway, which regulates the synthesis of cholesterol, and produces the required intermediate proteins geranylgeranylation and farnesylation [100] (Figure 3). 


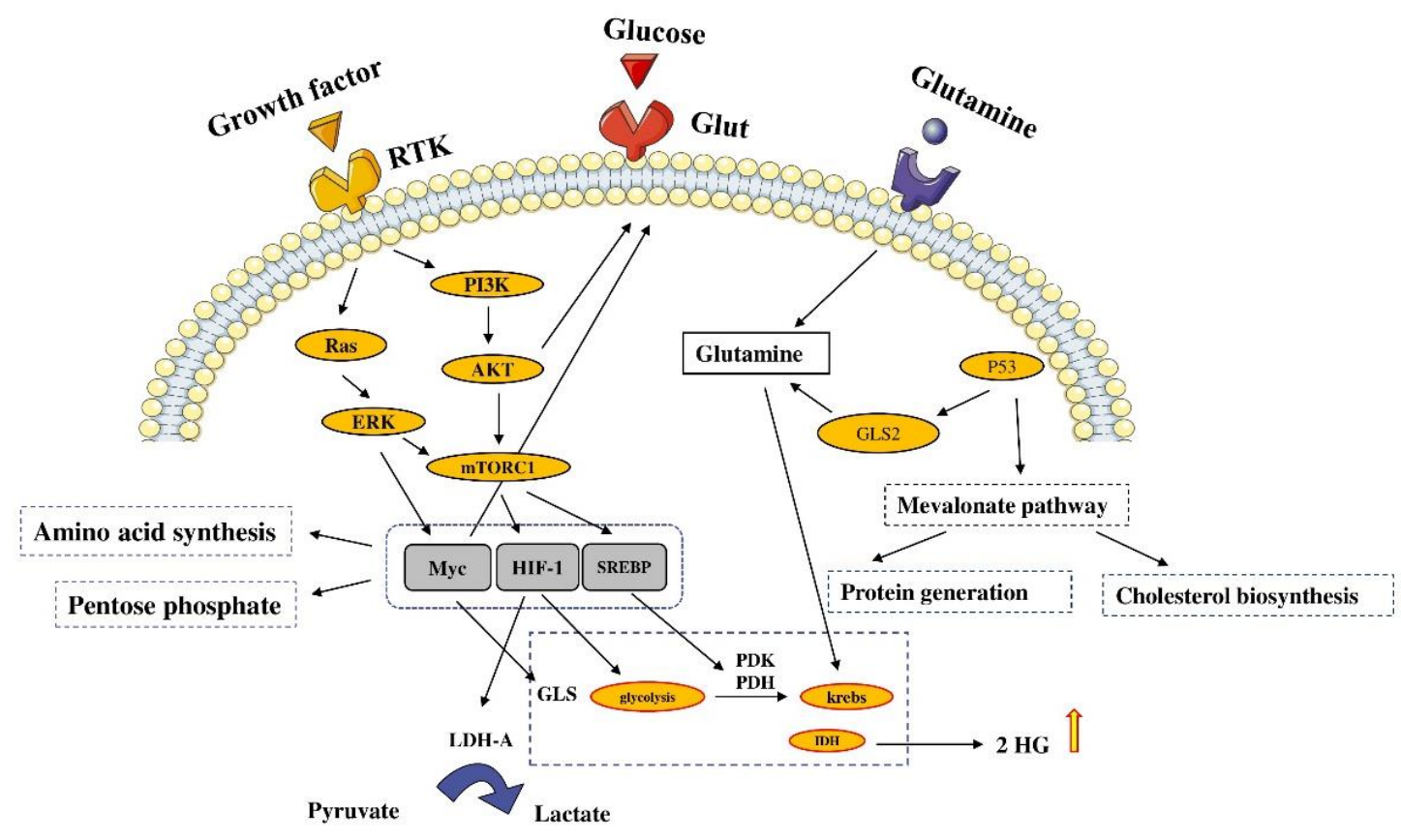

Figure 3. Signaling pathway and cell metabolism. Dysregulation of metabolism is a common phenomenon in cancer cells. Many different mutation genes, such as isocitrate dehydrogenase 1 (IDH1) and 2 (IDH2) mutations, can increase metabolites in cancer cells.

\subsection{Cell migration}

Cell migration is regulated by adhesion receptors, chemokines, growth factors, and other stimulators [101,102], most of which are dysregulated in cancer signaling. The result of changes in these pathways is extremely contextual and isoform dependent, as is with other procedures controlled by oncoprotein signaling. For instance, AKT1 explicitly represses migration by inhibiting ERK, the transcription factor NFAT, TSC2, or actin-bundling induced by phosphopalladin. On the other hand, AKT2 enhances migration by regulating integrin activity and epithelial-mesenchymal transition (EMT) [103]. It should be noted that EMT is not crucial for the dissemination of infection and tumor cells. EMT is associated with several physiological processes, including wound regeneration, gastrulation, and morphogenesis splitting [104]. This type of development is regulated by various highly organized processes, including TNF, Notch, Wnt, transforming growth factor (TGF) $\beta$, and some growth factors. EMT is characterized by the dysregulation of E-cadherin and junctional adhesion molecules [105], loss of apical-basal polarity, anchorage independence in some contexts, the adoption of a fibroblast-like appearance, and the acquisition of stem or progenitor-cell phenotypes. These would augment the capacity of the cell to invade other tissues and trigger tumors at distant sites. In certain circumstances, it is stipulated that the PI3K-AKT and Ras-ERK pathways promote EMT when hyperactivated in conjunction with other involved pathways (e.g., Notch, Wnt, and TGF $\beta$ signaling) [106]. Several transcription factors, such as Slug, Snail, ZEB, and Twist, also play pivotal roles in enhancing EMT and are modulated by AKT and ERK. For instance, AKT could phosphorylate $\mathrm{I} \kappa \mathrm{B}$ kinases that control NF- $\kappa \mathrm{B}$, a transcription factor that stimulates Snail. Additionally, AKT phosphorylates and inactivates GSK3, which increases Snail ubiquitin-dependent degradation [107]. Activation of AKT then stimulates Snail, further enhancing EMT. Furthermore, HNRNP E1, a protein that stimulates translational elongation on EMT promoting transcripts, is phosphorylated by AKT2 [108]. In addition to other gene expression programs that regulate phenotypic modifications related to EMT, Activator Protein 1 (AP-1) can stimulate transcription factors that enhance EMT and is modulated by the Ras-ERK pathway. This involves the stimulation 
of $\mathrm{E}$ cadherin, fibronectin, vimentin, integrin heterodimers (e.g., aVb6 and a5b1), and cytokeratin down-regulation polarity proteins (e.g., LGL, PATJ, and Crumbs), all of which promote cell motility. Precisely, by inhibiting ERK (which stimulates ZEB1), the polarity protein Scribble retains cell-cell ties [109,110]. Notch signaling could also promote tumor migration through Notch3 activation [48]. Ultimately, aberrant regulation of both PI3K-AKT and Ras-ERK is capable of playing a significant function in cancer development, as shown in Figure 4.

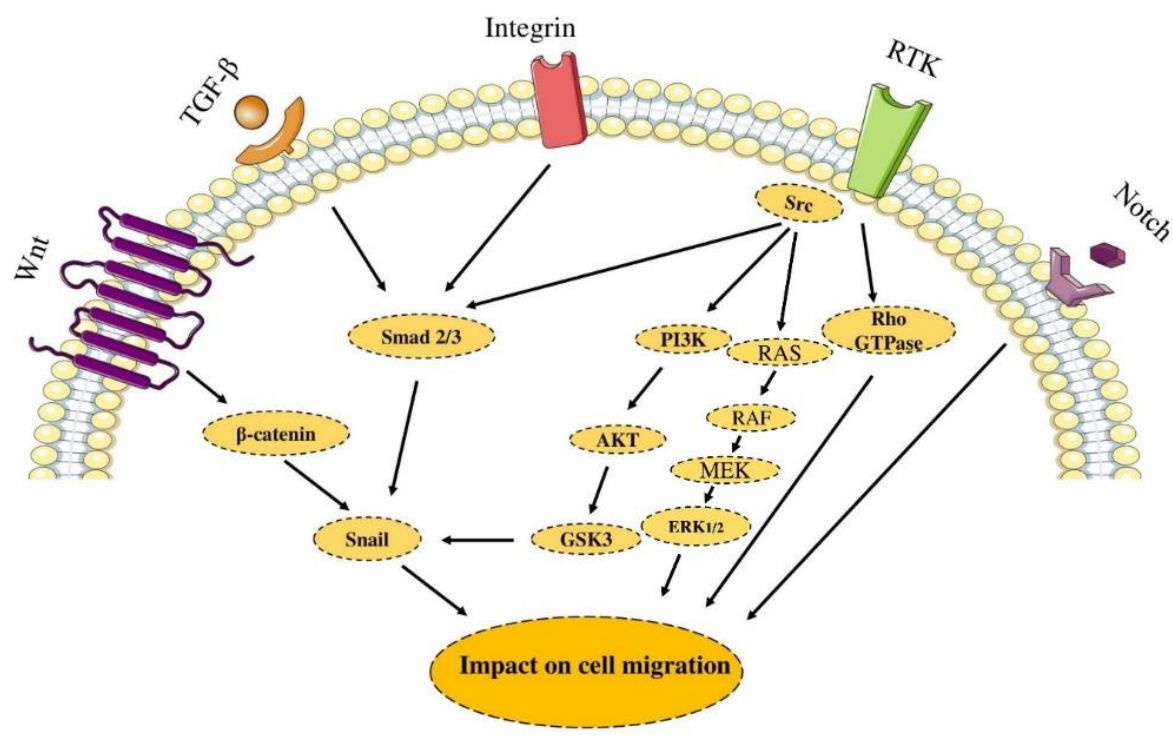

Figure 4. Signaling pathway and cell migration. Metastasis is a multistep process that includes migration and invasion of cancer cells, both of which are hallmarks of malignancy. Migration is regulated by adhesion receptors, chemokines, growth factors, and other stimulators.

\subsection{Cell polarity}

Polarity proteins are essential for maintaining tissue architecture. Three complexes of proteins possess essential functions in polarity control: the complex of Scribble, Par, and Crumbs. Dysregulation of these processes is found in tumors where aberrant expression of PI3K-AKT and Ras-ERK signaling pathways are involved. For instance, Scribble inhibits ERK activity by functioning as a scaffold to link it to the protein phosphatase PP1G [110,111]. Loss of Scribble stimulates H-Ras activation [112], whereas Ras and Myc stimulate tumor formation [113]. Moreover, loss of the Par3 polarity protein contributes to enhanced accumulation of several cell designs $[114,115]$ through mechanisms such as JAK/STAT3 signaling PKC-dependent activation. This stimulates the expression of MMP9, a metalloproteinase, which consequently causes the death of ECM. It also stimulates enhanced activation of Rac and invasion, resulting in reduced cell-cell adhesion [116,117].

\subsection{Cell differentiation}

Among cancers that disrupt the equilibrium between cell differentiation and proliferation, acute promyelocytic cancer, such as myeloblasts, is decreased to differentiate into mature erythrocytes. This results from a translocation that creates a protein fusion component known as PML and a receptor of retinoic acid (RAR) [118]. The PML-RAR fusion protein inhibits and targets RAR genes that generally trigger differentiation, therefore blocking the RAR signal. Additional mutations then 
cause the over-proliferation of undifferentiated myeloblasts [119]. Similarly, in colon crypts, Wnt $/ \beta$-catenin signaling [119] usually keeps enterocytes in an undifferentiated state in colon cancer. However, as APC cells migrate up to the luminous intestine surface, they cause $\beta$-catenin degradation, which blocks the signaling. However, the APC tumor suppressor mutation implies that $\beta$-catenin is not demolished and can retain the cells in an undifferentiated state as they die. Developmental signals may also enhance cancer development since they promote the proliferation of cells. For instance, mutations that trigger notch leading to acute lymphocytic leukemia [120] can promote the cell cycle and suppress $\mathrm{T}$ cell apoptosis. Remarkably, the notch can function in some tissues as a tumor suppressor [121], illustrating the significance of its signaling pathway. Hedgehog signaling pathway activation [122] occurs in medulloblastomas and basal cell carcinomas through mutations in the patched receptor, thereby promoting cell proliferation. The Hedgehog signaling pathway can also promote tumor differentiation [73,123]. Hedgehog signaling is upregulated in several malignancies through autocrine loops that influence embryonic gut tissues. The signaling mechanisms of PI3K-AKT and Ras-ERK are triggered by fibroblast growth factor (FGF), insulin-like growth factor (IGF), and epidermal growth factor (EGF), all of which can be considered behavioral signaling mechanisms. For instance, FGF4/8 signaling stimulates the Ras-ERK pathway to promote EMT, a pathway recapitulated by various cancers throughout gastrulation [124]. Furthermore, the background is crucial. That is, while FGF signaling might influence angiogenesis (see below) as well as cell growth, migration, and apoptosis (see above), it may also have tumor repressive effects and retain cells in a distinguished non-proliferative state. The expression of FGFR2 is decreased in prostate and bladder cancer and increased in gastric cancers [2]. Furthermore, Notch signaling could affect cellular differentiation through Hes1 $[48,49]$ and glioma-associated oncogenes (Gli2).

\section{Cancer and Extracellular matrix signaling}

The extracellular matrix (ECM) is a scaffold that supports tissues and provides migration and adhesion substrate along with a source of bioactive molecules for cells. It is continuously being renovated away from a static framework, and its conformation plays a pivotal role in controlling the behavior of the cell. Collagen, laminin, fibronectin, and several other ECM elements act as ligands triggering integrin development. ECM signaling, in addition to other proteins such as tyrosine kinase FAK, results in the activation of canonical processes such as PI3K-AKT and Ras-ERK signaling. This scaffold connects integrins with cytoskeletal proteins, adapters, and enzymes, all of which transmit signals from complex matrix adhesion. Additionally, FAK controls p53 and microRNA family members, which regulate apoptosis and the epithelial phenotype [125].

\subsection{Integrins and tumorigenesis}

Integrins are heterodimeric receptors of the cell surface that mediate ECM interactions and play a major role in the tumor microenvironment. Transmembrane structures in the cytoskeleton connect to both $\alpha$ and $\beta$ subunits $[126,127]$. Integrins are present on virtually all surfaces of nucleated cells. Therefore, they are active in tumor cells and stromal cells, allowing for recent thorough assessments of integrin functions in tumor progression $[128,129]$. Cancer-associated fibroblasts (CAFs) are the major promoters of tumorigenic characteristics and initiate ECM remodeling in the tumor, triggering the survival, migration, and proliferation of the tumor cells. Moreover, the ECM functions as a reservoir of cytokines and growth factors contributing to the bidirectional communication of the tumor cells and stroma $[130,131]$. Recent studies have also illustrated the correlation between CAFs and ECM regulating the metastatic niche and chemoresistance [132]. Cancer-associated fibroblasts broadly infiltrate the tumor stroma, comprising two different cellular populations: cells ancillary to the epithelium and cells myofibroblastic differentiation whose phenotype is characterized by alpha-SMA expression. These cells also exert a direct modulation to proliferative cancer potential, tumoral angiogenesis, disseminative potential, and aggressiveness in both solid [133-135] and hematological malignancies [136,137]. 


\subsection{Collagen-binding integrins}

The $\alpha 1$ and $\alpha 2$ integrin chains have also been delineated in dermal myofibroblasts with limited data available on their CAF activity $[138,139]$. These chains are generally dispersed and may also be found in cancer cells, immune cells, and vascular tissue [140-142]. It has been shown in collagen gels that $\alpha 11$-mediated features that synergize through TGF $\beta$ depend on JNK signals [143]. Studies have also shown a significant function for $\alpha 11$ in the endogenous stroma related to cancer metastasis and development [144]. As $\alpha 11 \beta 1$ is limited to mesenchymally shaped fibroblasts, $\alpha 11$ may be a component of a gene pattern, causing the incursion of metastasizing neurons in breast cancer [145]. Moreover, it was illustrated that the siRNA knockdown of $\alpha 11$ decreases the invasion of cancer cells, as seen in Figure 5.

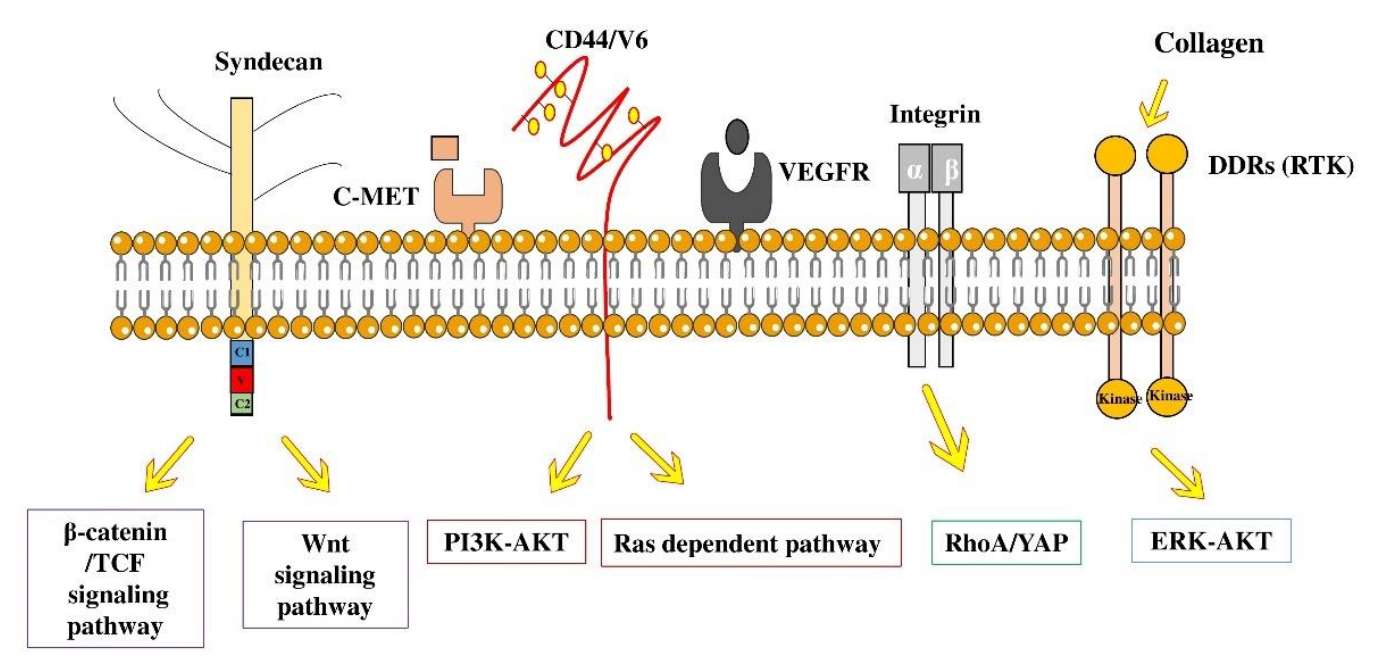

Effect on Proliferation, Metastases, Cell differentiation, and Migration

Figure 5. Extracellular matrix and cancer signaling. There are many different types of pathways involved in proliferation, metastasis, cell differentiation, and migration.

\subsection{EDA+ fibronectin-binding integrins}

Extra domain A-containing (EDA+) fibronectin serves as a biomarker of activated fibroblasts in cancer stroma, scar regeneration, and fibrosis [146,147]. Suggested receptors for the addition of EDA+ fibronectin in fibroblasts include $\alpha 4 \beta 1$ and $\alpha 9 \beta 1$, which bind at a cryptic site [148]. TGF $\beta$ triggered myofibroblast differentiation was shown to require EDA+ Fibronectin [149].

\subsection{Integrin function and CAF differentiation}

Regardless of the stroma's role, fibroblasts are most frequently activated in tumor stroma. Fibroblasts are differentiated into myofibroblasts characterized by $\alpha$-SMA and EDA+ fibronectin expression $[131,146]$. Two processes for the differentiation of progenitors into myofibroblasts are of significant importance: cell contraction followed by a reorganization of the ECM and TGF $\beta$ signaling [150].

\subsection{CAF integrins and tumor cell proliferation}

Two other main loops maintain the activated state of CAFs, and other paracrine processes influencing tumor cells or stem angiogenesis. For instance, tumor-secreted bidirectional PDGF-CC 
attracts PDGF $\alpha$ R-positive fibroblasts, thus influencing the production of FGF-7 and FGF-2 by CAFs, and plays a role in cell angiogenesis [151].

\subsection{CAF integrins and tumor stiffness}

The role of matrix stiffness may be to modulate the activation of TGF $\beta$ on CAFs. The latter probably has a fundamental role in the activation of the former within the tumor stroma. Accumulating evidence has demonstrated how a stiff matrix sensitizes the TGF $\beta$-LAP complex for activation $[152,153]$.

\subsection{Integrin function in CAF-promoted metastasis and invasion}

In vivo research has indicated that integrins on contractile CAFs are an incorporated component of matrix tunneling, thereby clearing the path for tumor cells to be invaded $[33,154,155]$. This method is accompanied by tissue, tumor, and stage-specific induction of various MMPs [154,156,157].

\subsection{Discoidin domain receptors}

Discoidin domain receptors (DDRs) are the tyrosine kinases receptors (RTKs) whose function is to bind to various collagens and MMP $[158,159]$. In this RTK class, there are two strongly associated receptors: DDR1 and DDR2 [160]. These DDRs also regulate basic procedures at the cellular stage, such as cell differentiation, proliferation, migration, and survival, typically controlled through RTKs. They also lead to the remodeling of ECM by regulating cell metalloproteinases' expression and function $[159,161,162]$. Several malignancies are defined by dysregulation or activity of one or more RTKs, whose dysregulated activity could promote cancer development. Thus, it is not unusual that cancer has changed the activity of DDRs. Dysregulated DDR signaling is believed to lead to a broad spectrum of cancers, including solid tumors and blood cancers. Examples of this include brain, head, neck, lung, prostate, breast, ovarian, kidney, pancreatic cancer, lymphoma, and leukemia [161]. As several separate functions have emerged, the role played by DDRs in malignancy is probably multifaceted. For example, DDR1 can regulate tissue migration, metastasis, and chemoresistance $[161,163,164]$. Correspondingly, DDR2 is essential for promoting metastasis [165] and could act as an oncogenic trigger in pulmonary disease [166].

\subsection{Cell surface proteoglycans}

Studies have indicated that proteoglycans comprise a core protein that is covalently connected to one or more glycosaminoglycan chains. Only a small number of types of glycosaminoglycans have been identified in mammals, including keratan sulfate (KS), hyaluronan (HA), heparan sulfate (HS), and chondroitin sulfate (CS) with closely-related dermatan phosphate (DS) [167]. HA is not sulfated or connected to a core protein and can be cross-linked with ECM proteins [168]. However, it is recognized as a critical ECM component for tumor biology [169], as indicated in Figure 5.

\subsubsection{The classes of cell surface proteoglycans}

There are two main types of cell surface proteoglycan, syndecans, and glypicans, both of which have a history of evolution. Syndecans are connected via a phospholipid anchor [170] to the cell membrane. Additionally, ECM macromolecules with heparin-binding characteristics have been discovered in all types of matrices. In wound repair processes, glycoproteins like fibrinogen, fibronectin, and Von Willebrand factor, are critical and may be obtained from the circulation [171]. Other glycoproteins, including thrombospondins, tenascins, CTGF/Cyr61/NOV (CCN) genes, and matricellular proteins, are also produced in disease or response to tissue harm, as is the case with tumors [172,173]. These processes require engagement and integration of RTKs with continuous ERK1,2 signaling [174]. This motif is prevalent in other proteoglycans on the cell surface, such as CD44 and syndecans. The enhanced manifestation of CSPG4 (with upregulated collagen VI) in individuals with soft tissue sarcoma is considered a prognostic factor [175]. 


\subsubsection{CD44-specific signaling}

CD44 has drawn much attention in tumor biology because tumor progression is strongly linked with the manifestation of some splice variants [39]. The version CD44v6 may function as a co-receptor by a receptor of the c-Met, or vascular endothelial growth factor where the ligand of the hepatocyte growth factor binds to both receptors [176]. In these examples, downstream signaling is complicated as it incorporates Ras-dependent signals for preservation and opposition to apoptosis and Rac-1, which enhances invasion and migration and actin cytoskeletal organization [177]. In reaction to the ECM relationships [178], the CD44v6 isoform can also detect the PI3K/AKT mechanism. CD44 is also of great importance as a cancer stem cell indicator in breast, prostate, pancreatic, and colon cancer [179].

\subsubsection{Syndecans and cancer}

Even though there is little evidence that syndecans mutations play a crucial role in tumor progression, several trials have revealed syndecan activity changes in solid and blood cancers $[180,181]$. However, it is uncertain whether expressed syndecans have a critical role in tumor progression participants or act as bystanders. Moreover, syndecan-1 activation has been correlated to tumor development and malignancy in myeloma [182]. In research regarding a mammalian carcinogenesis model of the mouse, it was elucidated that syndecan-1 is necessary for Wnt1 to promote tumor formation [183], which seems to be associated with $\beta$-catenin/TCF signaling [183].

\section{Angiogenesis}

Like all tissues, tumor cells require blood flow. The creation of new blood vessels (angiogenesis) through growth and incorporation of endothelial cells acquires co-opting procedures that frequently operate in wound healing in both in vivo and in vitro systems [184,185]. Signals for angiogenesis include angiopoietin, interleukin (IL) 8, FGF, VEGF, and PDGF. The PI3K-AKT signaling pathway regulates angiogenesis induction and stabilization of the vessel $[118,186,187]$, with potential multifaced therapeutic widow in a broad spectrum of malignancies $[188,189]$ mHIF1 is responsible for stimulating the synthesis and secretion of VEGF in cancer cells. PI3K-AKT signaling increases HIF1 intensity and hyperactivation and is also a significant element of angiogenesis. The HIF1 function is regulated by the Von Hippel-Lindau (VHL) core, an E3 ligase element that stimulates its ubiquitin-dependent degradation under normoxic conditions. VHL acts as a cancer suppressor, and a variety of tumors are involved in inactivating its genes. The PI3K-AKT pathway also regulates other angiogenic factors like angiopoietins and nitric acid. The structure of unusual blood vessels has been shown to cause constitutive endothelial stimulation of AKT1. VEGF is sequestered in the ECM after its secretion and cannot impact endothelial cells until released by MMP9. These are secreted by macrophages and monocytes in the microenvironment of the tumor, thus highlighting the significance of immune cells in angiogenesis and the presence of a broader signaling network involving cancer cells. The thrombospondins-1,2 (TSP-1 and TSP-2) are active endogenous angiogenesis inhibitors. They prevent angiogenesis by directly impacting the development, growth, proliferation, and apoptosis of endothelial cells and antagonizing VEGF function [190]. TSP-1 and TSP-2 rates are essential determinants of angiogenesis initiation and the local volume of TSP-1 in the tissue, which is a significant determinant of tumor growth [191]. Therefore, inhibition of TSPs may be a critical inhibition factor for angiogenesis in different types of cancer cell lines and in vivo [192]. The bone marrow-derived cellular population also orchestrates angiogenesis. In the last years, the bone marrow niche emerged as a major determinant of tumor angiogenesis, representing a major source of several cytotypes [193-195]. Macrophages, neutrophils, mast cells, and myeloid-lineage derived precursors actively participate in cancer-related inflammation by providing a nursing environment orchestrated by innate immunity [196]. Epigenetic and cell-derived membrane vesicles, such as exosomes and microvesicles, represent a novel, greatly promising group of miRNA carriers involved in angiogenesis and immune-patrolling. Furthermore, they expressly target cells with reduced off-target activity. Indeed, microvesicles were recently uncovered to be effective in 
VEGF-targeted therapy in gastric tumor. This results in an interface between the angiogenic development and the tumor immune-microenvironment [197]. Additionally, several cell types cooperate in preventing the antiangiogenic drug activity on the endothelium [198]. A plethora of bone marrow-derived progenitors migrate within the cancer milieu, actively participating in the neovascular wall, assuming endothelial or pericyte differentiation and functions [199-201], and modulating immune response [202,203].

\section{Inflammation}

Inflammatory cells can secrete FGF and EGF, which are essential to PI3K-AKT and Ras-ERK signaling regulators in cancer cells. They also generate colony-stimulating factor 1 (CSF1), a key signal that induces macrophages to secrete more EGF. VEGF and MMPs are produced by immune cells that stimulate angiogenesis [204]. In both tumor-associated inflammatory cells and cancer cells, signaling via the transcription factor NF- $\mathrm{kB}[205]$ is essential because it can support cell proliferation and growth, thus promoting cytokine production like TNF. In some lymphoid malignancies, oncogenic diseases influence NF- $\mathrm{kB}$ or downstream effectors like MALT1 and Bcl10. Moreover, in most tumors, NF- $\kappa B$ activation usually increases cytokines production. The pathway's tumor-promoting activity derives from its ability to induce the expression of pro-inflammatory cytokines like Interleukin 6 (IL-6), Tumor necrosis factor-alpha (TNF- $\alpha$ ), Interleukin 1(IL-1), and Interleukin 8(IL-8) via premalignant epithelial cells and immune/inflammatory cells. Additionally, other cytokines, including Interleukin 11 (IL-11), enhance concentrations of phospho-STAT3 [63], thus promoting cell proliferation. A similar process occurs in hepatocellular carcinoma and prostate cancer [206]. Activation of NF-kB also contributes to more TNF- $\alpha$ and prostaglandin E2 synthesis, promoting cell proliferation and cell polarity.

\section{Single-cell omics for cancer signaling pathways}

As aforementioned, although different pathways and genes have been identified for their roles in cancer development, there is yet to be a comprehensive approach to cancer treatment. With the wide adoption of high-throughput omics strategies for analyzing biological samples including transcriptomics, genomics, proteomics, and metabolomics, each study produces regular data (Figure 6) $[207,208]$. On the other hand, systems biology shows biological systems as dynamic hierarchical systems whose actions cannot be reduced to the linear total of their component functions [209]. A systems biology strategy, when applied to a complicated disease like cancer, can imitate conventional, usually intrusive, and costly, experience-based solutions [210]. New medications are designed in a multidisciplinary and systemic manner (Figure 6).

During the last decade, the exponential development of high-throughput technologies (such as microarray and next-generation sequencing (NGS)) has produced new gene expression profiling strategies [211]. More recently, the single-cell analysis allowed discovering new dimensions that will possibly monitor the trajectories of distant cell lineage in tumor progression. The data produced via single-cell multi-omics uncovered the main biological processes, cellular heterogeneity mechanism, and mechanism of resistance. The insights obtained from the single-cell analysis allowed a deeper understanding of cancer and the development of successful strategies for treatment [212].

\subsection{Dissecting key cellular and molecular functions in cancers}

Intratumor heterogeneity inside the tumor mass is a key characteristic of malignancy and has been stated in several types of tumors. For example, in the case of breast cancer, the characterization of this heterogeneity at a molecular level is a major challenge for efficient therapy. In a recent study, Cho recognized an ERBB pathway activated triple-negative cell population by data from single-cell transcriptome analysis (scRNA-seq). While the differential expression of ERBB2, ESR1, and PGR as subtyping marker genes was not altered in the bulk RNA-seq data, but the scRNA-seq data revealed intratumor heterogeneity. This outcome not only confirmed that ERBB signaling is stimulated via an 
indirect way but also that the molecular subtype is changed on a single-cell level. His data suggest a distinct view of breast cancer subtypes and can lead to contributing to precision medicine [213].

\subsection{Molecular mechanisms of drug resistance}

In the treatment of human tumors, drug resistance is a big obstacle. Although different types of cancer therapies including immunotherapy and chemotherapy are often primarily successful, some of the patients show drug resistance and progress to metastatic steps [214]. Major areas of research include the clarifying of resistance mechanisms as well as the discovery of predictive response biomarkers. Single-cell omics approaches can profile heterogeneity and the tumor microenvironment (TME) from pre-treatment samples through clinical data, or those collected pre and post-treatment to address these issues (Figutre 6). For example, two melanoma studies by scRNA-seq stated microphthalmia-associated transcription factor, AXL, and dopachrome tautomerase signatures related with RAF/MEK-inhibitor resistance [215,216]. Furthermore, scRNA-seq data analysis of circulating tumor cells in prostate cancer recognized activated non-canonical Wnt signaling pathway in resistance of androgen receptor inhibitors [217].

\subsection{Understanding of the pathways targeted by immunotherapy agents}

Immunotherapy has revolutionized cancer therapy in the past decade. The lack of precise understanding of the mechanisms of action of immunotherapies requires the creation and implementation of pipelines which can initially identify new therapeutic targets and afterward analyze the effects of therapeutic agents in TME at high resolution on all the cells and molecular pathways. The recent increase in the production of single-cell genomic technologies has opened up unique possibilities for such research [218]. These tools allow the therapy 's impact in a complex environment to be characterized in-depth, identifying the target cells and pathways and the secondary cellular effects in the environment.

For a broad variety of human cancers, checkpoint blockade with PD-1 and CTLA-4 inhibitor-specific antibodies may induce durable responses. Nevertheless, there is still a limited understanding of the immunological pathways responsible for serious inflammatory side effects. Louma et al. described the side effect of the checkpoint blockade through single-cell transcriptome data analysis of immune cell populations in colitis disease. A remarkable accumulation of CD8+ T cells with extremely cytotoxic and proliferative states and no indication of regulatory depletion of $\mathrm{T}$ cells was found. Sequence evaluation of the $\mathrm{T}$ cell receptor showed that a large fraction of colitis-associated CD8+ T cells originated from tissue-resident populations, explaining the recurrent early onset of colitis symptoms after initiation of therapy. Cytokines, chemokines, and surface receptors which can consider as therapeutic targets for colitis disease and possibly other inflammatory side effects of checkpoint blockade were also identified in their study. 


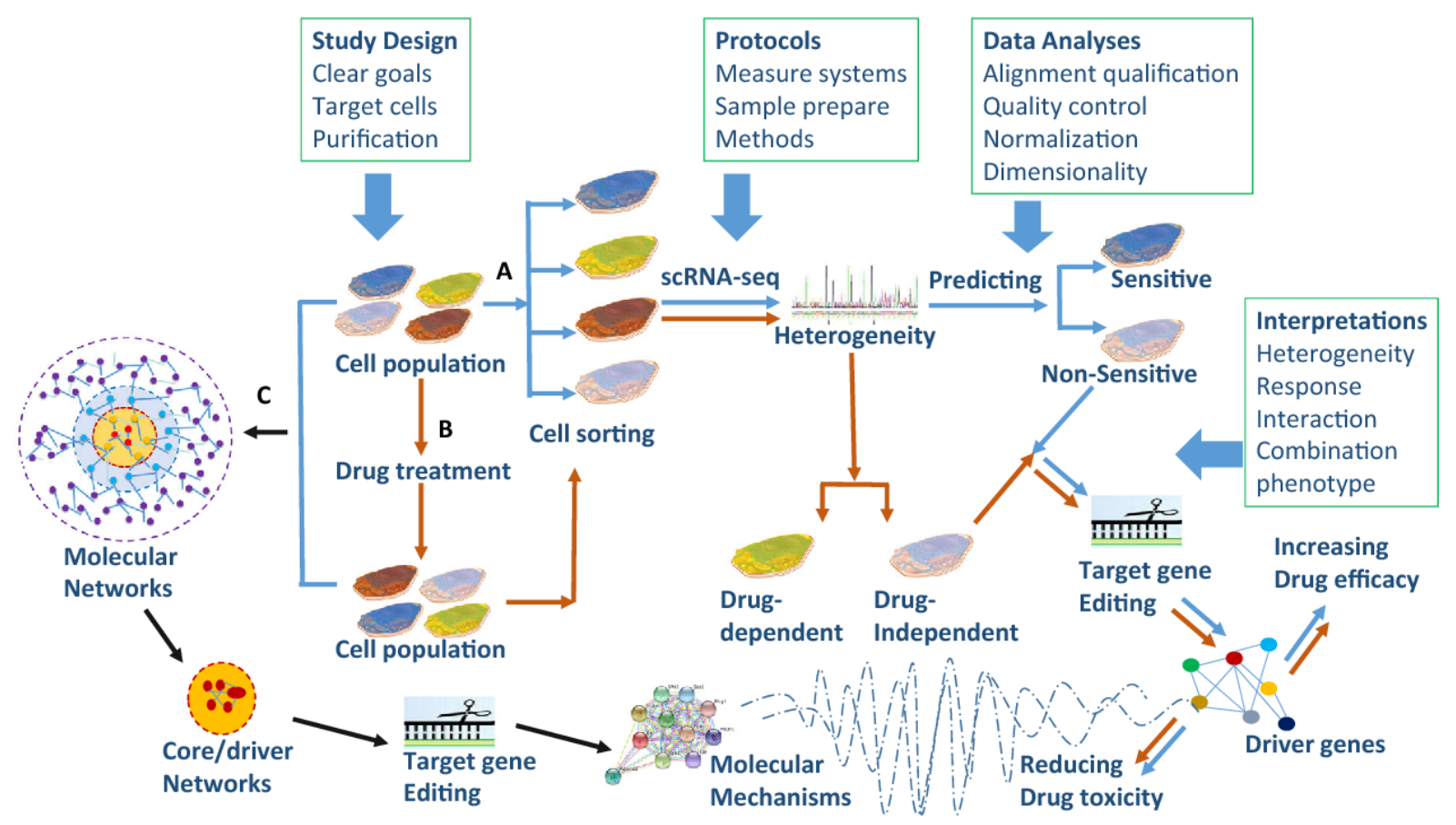

Figure 6: Single-cell RNA sequencing application in drug-response prediction. Targeted cell populations are selected from human organs/tissues and then one type of cell population can be sorted. Drug-dependent gene mutations and drug specificity of targeted genes can be defined after selected cells are treated with targeting drugs (b, brown arrows). On the other hand, gene sequences and epigenetics of selected cells can be measured before the cell sorting (c, black arrows), in order to compare the cell population with single-cell sequences. Molecular mechanisms, drug efficacy, and toxicity of identified core/driver genes and networks can be furthermore validated by editing target genes. Reprinted with permission from [219].

\section{Conclusion and future prospective}

Over the past 20 years, there have been substantial advances in our knowledge about the signaling pathways of cancers. These advances can pave the road for developing novel treatments to overcome drug resistance in affected patients. Since the signal-cell sequencing has provided ample opportunity to precisely determine the genetic mutations and the involved pathways in individual tumors, this approach has become a promising approach to overcoming drug resistance. Furthermore, this approach can further our knowledge about the personalized biomarkers and properties of cancer, which aid the developing forefront treatment. More awareness of intracellular signaling networks and cross-talks among pathways and extracellular is needed in order for this approach to thrive in the coming decades. 
Author Contributions: Conceptualization, A.D., Z.R., H.S., and B.B.; resources, S.T., N.J.T., M.A.S., O.K., R.V.A., A.A., P.K.S., N.T., N.A.; original draft preparation A.D., Z.R., H.S.; review and editing, A.A., N.S., B.B.; supervision, B.B.; funding acquisition, N.S. All authors have read and agreed to the published version of the manuscript.

Funding: This research was funded by the Apulian Regional Project “Medicina di Precisione" to N.S.

Conflicts of Interest: The authors declare no conflict of interest. 


\section{References}

1. Sanchez-Vega, F.; Mina, M.; Armenia, J.; Chatila, W.K.; Luna, A.; La, K.C.; Dimitriadoy, S.; Liu, D.L.; Kantheti, H.S.; Saghafinia, S. Oncogenic signaling pathways in the cancer genome atlas. Cell 2018, 173, 321-337. e310.

2. Turner, N.; Grose, R. Fibroblast growth factor signalling: from development to cancer. Nature Reviews Cancer 2010, 10, 116 .

3. Hanahan, D.; Weinberg, R.A. The hallmarks of cancer. ce//2000, 100, 57-70.

4. Solimini, N.L.; Luo, J.; Elledge, S.J. Non-oncogene addiction and the stress phenotype of cancer cells. Cell 2007, 130, 986-988.

5. Weinberg, R. The Biology of Cancer (Garland, New York). 2013.

6. Komiya, Y.; Habas, R. Wnt signal transduction pathways. Organogenesis 2008, 4, 68-75, doi:10.4161/org.4.2.5851.

7. Shi, L.; Wang, X. Role of osteopontin in lung cancer evolution and heterogeneity. In Proceedings of Seminars in Cell \& Developmental Biology; pp. 40-47.

8. Da Vià, M.C.; Solimando, A.G.; Garitano-Trojaola, A.; Barrio, S.; Munawar, U.; Strifler, S.; Haertle, L.; Rhodes, N.; Teufel, E.; Vogt, C. CIC mutation as a molecular mechanism of acquired resistance to combined BRAF-MEK inhibition in extramedullary multiple myeloma with central nervous system involvement. The oncologist 2020, 25, 112

9. Wang, W.; Gao, D.; Wang, X. Can single-cell RNA sequencing crack the mystery of cells? Cell Biology and Toxicology 2018, 34, 1-6, doi:10.1007/s10565-017-9404-y.

10. Santini, D.; Loupakis, F.; Vincenzi, B.; Floriani, I.; Stasi, I.; Canestrari, E.; Rulli, E.; Maltese, P.E.; Andreoni, F.; Masi, G. High concordance of KRAS status between primary colorectal tumors and related metastatic sites: implications for clinical practice. The oncologist 2008, 13, 1270.

11. Navin, N.; Hicks, J. Future medical applications of single-cell sequencing in cancer. Genome medicine 2011, 3,31 .

12. Ren, X.; Kang, B.; Zhang, Z. Understanding tumor ecosystems by single-cell sequencing: promises and limitations. Genome biology 2018, 19, 1-14.

13. Kamaruzman, N.I.; Aziz, N.A.; Poh, C.L.; Chowdhury, E.H. Oncogenic Signaling in Tumorigenesis and Applications of siRNA Nanotherapeutics in Breast Cancer. Cancers 2019, 11, doi:10.3390/cancers11050632.

14. Futreal, P.A.; Coin, L.; Marshall, M.; Down, T.; Hubbard, T.; Wooster, R.; Rahman, N.; Stratton, M.R. A census of human cancer genes. Nature reviews cancer 2004, 4, 177.

15. Gnoni, A.; Licchetta, A.; Scarpa, A.; Azzariti, A.; Brunetti, A.E.; Simone, G.; Nardulli, P.; Santini, D.; Aieta, M.; Delcuratolo, S. Carcinogenesis of pancreatic adenocarcinoma: precursor lesions. International journal of molecular sciences 2013, 14, 19731-19762.

16. Hanahan, D.; Weinberg, R.A. Hallmarks of cancer: the next generation. ce//2011, 144, 646-674.

17. Lotfipour, F.; Hallaj-Nezhadi, S.; Valizadeh, H.; Dastmalchi, S.; Baradaran, B.; Jalali, M.B.; Dobakhti, F.J.J.o.P.; Sciences, P. Preparation of chitosan-plasmid DNA nanoparticles encoding interleukin-12 and their expression in CT-26 colon carcinoma cells. 2011, 14, 181-195.

18. Vogelstein, B.; Kinzler, K.W. Cancer genes and the pathways they control. Nature medicine 2004, $10,789$.

19. Skoda, A.M.; Simovic, D.; Karin, V.; Kardum, V.; Vranic, S.; Serman, L.J.B.j.o.b.m.s. The role of the Hedgehog signaling pathway in cancer: A comprehensive review. 2018, 18, 8 .

20. Kim, J.Y.; Park, G.; Krishnan, M.; Ha, E.; Chun, K.-S.J.A.r. Selective Wnt/ $\beta$-catenin Small-molecule Inhibitor CWP232228 Impairs Tumor Growth of Colon Cancer. 2019, 39, 3661-3667. 
21. Nusse, R.; Clevers, H.J.C. Wnt/ $\beta$-catenin signaling, disease, and emerging therapeutic modalities. 2017, 169, 985-999.

22. Hirate, Y.; Sasaki, H.J.T.b. The role of angiomotin phosphorylation in the Hippo pathway during preimplantation mouse development. 2014, 2, 1181-1194.

23. Krishnamurthy, N.; Kurzrock, R.J.C.t.r. Targeting the Wnt/beta-catenin pathway in cancer: Update on effectors and inhibitors. 2018, 62, 50-60.

24. Jung, Y.-S.; Park, J.-I.J.E.; Medicine, M. Wnt signaling in cancer: therapeutic targeting of Wnt signaling beyond $\beta$-catenin and the destruction complex. 2020, 1-9.

25. Kim, M.; Jho, E.-h.J.B.r. Cross-talk between Wnt/ $\beta$-catenin and Hippo signaling pathways: a brief review. $2014,47,540$.

26. Luke, J.J.; Bao, R.; Sweis, R.F.; Spranger, S.; Gajewski, T.F.J.C.C.R. WNT/ $\beta$-catenin pathway activation correlates with immune exclusion across human cancers. 2019, 25, 3074-3083.

27. Argentiero, A.; De Summa, S.; Di Fonte, R.; lacobazzi, R.M.; Porcelli, L.; Da Vià, M.; Brunetti, O.; Azzariti, A.; Silvestris, N.; Solimando, A.G.J.C. Gene expression comparison between the lymph node-positive and-negative reveals a peculiar immune microenvironment signature and a theranostic role for WNT targeting in pancreatic ductal adenocarcinoma: A pilot study. 2019, 11, 942.

28. Galluzzi, L.; Spranger, S.; Fuchs, E.; López-Soto, A.J.T.i.c.b. WNT signaling in cancer immunosurveillance. 2019, 29, 44-65.

29. Mansoori, B.; Mohammadi, A.; Shirjang, S.; Baradaran, B.J.C.C. HMGI-C suppressing induces P53/caspase9 axis to regulate apoptosis in breast adenocarcinoma cells. 2016, 15, 2585-2592.

30. Moon, S.-H.; Huang, C.-H.; Houlihan, S.L.; Regunath, K.; Freed-Pastor, W.A.; Morris IV, J.P.; Tschaharganeh, D.F.; Kastenhuber, E.R.; Barsotti, A.M.; Culp-Hill, R.J.C. p53 represses the mevalonate pathway to mediate tumor suppression. 2019, 176, 564-580. e519.

31. Sebastian, S.; Azzariti, A.; Silvestris, N.; Porcelli, L.; Russo, A.; Paradiso, A. p53 as the main traffic controller of the cell signaling network. Front Biosci 2010, 15, 1172-1190.

32. Sever, R.; Glass, C.K. Signaling by nuclear receptors. Cold Spring Harbor perspectives in biology 2013, 5, a016709.

33. Silvestris, N.; Tommasi, S.; Petriella, D.; Santini, D.; Fistola, E.; Russo, A.; Numico, G.; Tonini, G.; Maiello, E.; Colucci, G. The dark side of the moon: the PI3K/PTEN/AKT pathway in colorectal carcinoma. Oncology 2009, 77, 69-74.

34. Gorgoulis, V.G.; Halazonetis, T.D. Oncogene-induced senescence: the bright and dark side of the response. Current opinion in cell biology 2010, 22, 816-827, doi:10.1016/j.ceb.2010.07.013.

35. Vargas, J.; Feltes, B.C.; Poloni Jde, F.; Lenz, G.; Bonatto, D. Senescence; an endogenous anticancer mechanism. Frontiers in bioscience (Landmark edition) 2012, 17, 2616-2643.

36. Bansal, R.; Nikiforov, M.A. Pathways of oncogene-induced senescence in human melanocytic cells. Cell cycle (Georgetown, Tex.) 2010, 9, 2782-2788, doi:10.4161/cc.9.14.12551.

37. Parsons, D.W.; Jones, S.; Zhang, X.; Lin, J.C.; Leary, R.J.; Angenendt, P.; Mankoo, P.; Carter, H.; Siu, I.M.; Gallia, G.L., et al. An integrated genomic analysis of human glioblastoma multiforme. Science 2008, 321, 1807-1812, doi:10.1126/science.1164382.

38. Wood, L.D.; Parsons, D.W.; Jones, S.; Lin, J.; Sjoblom, T.; Leary, R.J.; Shen, D.; Boca, S.M.; Barber, T.; Ptak, J., et al. The genomic landscapes of human breast and colorectal cancers. Science 2007, 318, 1108-1113, doi:10.1126/science.1145720. 
39. Günthert, U.; Hofmann, M.; Rudy, W.; Reber, S.; Zöller, M.; Haußmann, I.; Matzku, S.; Wenzel, A.; Ponta, H.; Herrlich, P. A new variant of glycoprotein CD44 confers metastatic potential to rat carcinoma cells. Cell $1991,65,13-24$.

40. Zhang, Y.; Kwok-Shing Ng, P.; Kucherlapati, M.; Chen, F.; Liu, Y.; Tsang, Y.H.; de Velasco, G.; Jeong, K.J.; Akbani, R.; Hadjipanayis, A., et al. A Pan-Cancer Proteogenomic Atlas of PI3K/AKT/mTOR Pathway Alterations. Cancer cel/2017, 31, 820-832.e823, doi:10.1016/j.ccell.2017.04.013.

41. Sanchez-Vega, F.; Mina, M.; Armenia, J.; Chatila, W.K.; Luna, A.; La, K.C.; Dimitriadoy, S.; Liu, D.L.; Kantheti, H.S.; Saghafinia, S., et al. Oncogenic Signaling Pathways in The Cancer Genome Atlas. Cell 2018, 173, 321-337.e310, doi:10.1016/j.cell.2018.03.035.

42. Schaub, F.X.; Dhankani, V.; Berger, A.C.; Trivedi, M.; Richardson, A.B.; Shaw, R.; Zhao, W.; Zhang, X.; Ventura, A.; Liu, Y., et al. Pan-cancer Alterations of the MYC Oncogene and Its Proximal Network across the Cancer Genome Atlas. Cell systems 2018, 6, 282-300.e282, doi:10.1016/j.cels.2018.03.003.

43. Cohen, S.M.; Ellwein, L.B. Cell proliferation in carcinogenesis. Science 1990, 249, 1007-1011.

44. Dang, T.P. Notch, apoptosis and cancer. Advances in experimental medicine and biology 2012, 727, 199-209, doi:10.1007/978-1-4614-0899-4_15.

45. Zou, J.; Li, P.; Lu, F.; Liu, N.; Dai, J.; Ye, J.; Qu, X.; Sun, X.; Ma, D.; Park, J. Notch1 is required for hypoxia-induced proliferation, invasion and chemoresistance of T-cell acute lymphoblastic leukemia cells. Journal of hematology \& oncology 2013, 6, 3.

46. Aburjania, Z.; Jang, S.; Whitt, J.; Jaskula-Stzul, R.; Chen, H.; Rose, J.B. The Role of Notch3 in Cancer. The oncologist 2018, 23, 900-911, doi:10.1634/theoncologist.2017-0677.

47. Alqudah, M.A.; Agarwal, S.; Al-Keilani, M.S.; Sibenaller, Z.A.; Ryken, T.C.; Assem, M. NOTCH3 is a prognostic factor that promotes glioma cell proliferation, migration and invasion via activation of CCND1 and EGFR. PloS one 2013, 8, e77299, doi:10.1371/journal.pone.0077299.

48. Yuan, X.; Wu, H.; Xu, H.; Han, N.; Chu, Q.; Yu, S.; Chen, Y.; Wu, K. Meta-analysis reveals the correlation of Notch signaling with non-small cell lung cancer progression and prognosis. Scientific reports 2015, 5, 10338.

49. Ramakrishnan, V.; Ansell, S.; Haug, J.; Grote, D.; Kimlinger, T.; Stenson, M.; Timm, M.; Wellik, L.; Halling, T.; Rajkumar, S.V. MRK003, a $\gamma$-secretase inhibitor exhibits promising in vitro pre-clinical activity in multiple myeloma and non-Hodgkin's lymphoma. Leukemia 2012, 26, 340.

50. Gonnissen, A.; Isebaert, S.; Haustermans, K. Targeting the Hedgehog signaling pathway in cancer: beyond Smoothened. Oncotarget 2015, 6, 13899.

51. Jenkins, D. Hedgehog signalling: emerging evidence for non-canonical pathways. Cellular signalling 2009, 21, 1023-1034.

52. Scales, S.J.; de Sauvage, F.J. Mechanisms of Hedgehog pathway activation in cancer and implications for therapy. Trends in pharmacological sciences 2009, 30, 303-312.

53. Richardson, C.J.; Schalm, S.S.; Blenis, J. PI3-kinase and TOR: PIKTORing cell growth. In Proceedings of Seminars in cell \& developmental biology; pp. 147-159.

54. Diehl, J.A.; Zindy, F.; Sherr, C.J. Inhibition of cyclin D1 phosphorylation on threonine-286 prevents its rapid degradation via the ubiquitin-proteasome pathway. Genes \& development 1997, 11, 957-972.

55. Sears, R.; Nuckolls, F.; Haura, E.; Taya, Y.; Tamai, K.; Nevins, J.R. Multiple Ras-dependent phosphorylation pathways regulate Myc protein stability. Genes \& development 2000, 14, 2501-2514.

56. Rössig, L.; Jadidi, A.S.; Urbich, C.; Badorff, C.; Zeiher, A.M.; Dimmeler, S. Akt-dependent phosphorylation of p21Cip1 regulates PCNA binding and proliferation of endothelial cells. Molecular and cellular biology 2001, 21, 5644-5657. 
57. Burgering, B.M.; Medema, R.H. Decisions on life and death: FOXO Forkhead transcription factors are in command when PKB/Akt is off duty. Journal of leukocyte biology 2003, 73, 689-701.

58. Ogawara, Y.; Kishishita, S.; Obata, T.; Isazawa, Y.; Suzuki, T.; Tanaka, K.; Masuyama, N.; Gotoh, Y. Akt enhances Mdm2-mediated ubiquitination and degradation of p53. Journal of Biological Chemistry 2002, 277, 21843-21850.

59. Xu, X.; Hou, Y.; Yin, X.; Bao, L.; Tang, A.; Song, L.; Li, F.; Tsang, S.; Wu, K.; Wu, H. Single-cell exome sequencing reveals single-nucleotide mutation characteristics of a kidney tumor. Cel/2012, 148, 886-895.

60. Ma, L.; Zhang, G.; Miao, X.B.; Deng, X.B.; Wu, Y.; Liu, Y.; Jin, Z.R.; Li, X.Q.; Liu, Q.Z.; Sun, D.X. Cancer stem-like cell properties are regulated by EGFR/AKT/ $\beta$-catenin signaling and preferentially inhibited by gefitinib in nasopharyngeal carcinoma. The FEBS journa/2013, 280, 2027-2041.

61. Korkaya, H.; Paulson, A.; Charafe-Jauffret, E.; Ginestier, C.; Brown, M.; Dutcher, J.; Clouthier, S.G.; Wicha, M.S. Regulation of mammary stem/progenitor cells by PTEN/Akt/B-catenin signaling. PLoS biology 2009, 7, e1000121.

62. Fang, D.; Hawke, D.; Zheng, Y.; Xia, Y.; Meisenhelder, J.; Nika, H.; Mills, G.B.; Kobayashi, R.; Hunter, T.; Lu, Z. Phosphorylation of $\beta$-catenin by AKT promotes $\beta$-catenin transcriptional activity. Journal of Biological Chemistry 2007, 282, 11221-11229.

63. Harrison, D.A. The jak/stat pathway. Cold Spring Harbor perspectives in biology 2012, 4, a011205.

64. Thomas, C.; Gustafsson, J.-Å. The different roles of ER subtypes in cancer biology and therapy. Nature Reviews Cancer 2011, 11, 597.

65. Li, S.; Shen, D.; Shao, J.; Crowder, R.; Liu, W.; Prat, A.; He, X.; Liu, S.; Hoog, J.; Lu, C. Endocrine-therapy-resistant ESR1 variants revealed by genomic characterization of breast-cancer-derived xenografts. Cell reports 2013, 4, 1116-1130.

66. Robinson, D.R.; Wu, Y.-M.; Vats, P.; Su, F.; Lonigro, R.J.; Cao, X.; Kalyana-Sundaram, S.; Wang, R.; Ning, Y.; Hodges, L. Activating ESR1 mutations in hormone-resistant metastatic breast cancer. Nature genetics 2013, $45,1446$.

67. Toy, W.; Shen, Y.; Won, H.; Green, B.; Sakr, R.A.; Will, M.; Li, Z.; Gala, K.; Fanning, S.; King, T.A. ESR1 ligand-binding domain mutations in hormone-resistant breast cancer. Nature genetics 2013, 45, 1439.

68. Castoria, G.; Lombardi, M.; Barone, M.V.; Bilancio, A.; Di Domenico, M.; De Falco, A.; Varricchio, L.; Bottero, D.; Nanayakkara, M.; Migliaccio, A. Rapid signalling pathway activation by androgens in epithelial and stromal cells. Steroids 2004, 69, 517-522.

69. Renoir, J.-M.; Marsaud, V.; Lazennec, G. Estrogen receptor signaling as a target for novel breast cancer therapeutics. Biochemical pharmacology 2013, 85, 449-465.

70. Harvey, K.F.; Hariharan, I.K. The hippo pathway. Cold Spring Harbor perspectives in biology 2012, 4, a011288.

71. Lin, J.I.; Poon, C.L.; Harvey, K.F. The Hippo size control pathway-ever expanding. Sci. Signal. 2013, 6, pe4-pe4.

72. Duronio, R.J.; Xiong, Y. Signaling pathways that control cell proliferation. Cold Spring Harbor perspectives in biology 2013, 5, a008904.

73. Capaccione, K.M.; Pine, S.R. The Notch signaling pathway as a mediator of tumor survival. Carcinogenesis 2013, 34, 1420-1430.

74. Zhang, X.; Tang, N.; Hadden, T.J.; Rishi, A.K. Akt, FoxO and regulation of apoptosis. Biochimica et Biophysica Acta (BBA)-Molecular Cell Research 2011, 1813, 1978-1986.

75. Shen, H.-M.; Tergaonkar, V. NFkB signaling in carcinogenesis and as a potential molecular target for cancer therapy. Apoptosis 2009, 14, 348-363. 
76. Ghoda, L.; Lin, X.; Greene, W.C. The 90-kDa ribosomal S6 kinase (pp90rsk) phosphorylates the N-terminal regulatory domain of $\mathrm{I}_{\mathrm{K} B} \alpha$ and stimulates its degradation in vitro. Journal of Biological Chemistry 1997, 272, 21281-21288.

77. Kim, J.; Parrish, A.B.; Kurokawa, M.; Matsuura, K.; Freel, C.D.; Andersen, J.L.; Johnson, C.E.; Kornbluth, S. Rskmediated phosphorylation and $14-3-3 \varepsilon$ binding of Apaf-1 suppresses cytochrome c-induced apoptosis. The EMBO journal 2012, 31, 1279-1292.

78. Kaelin Jr, W.G.; McKnight, S.L. Influence of metabolism on epigenetics and disease. Cel/ 2013, 153, 56-69.

79. Plas, D.R.; Thompson, C.B. Akt-dependent transformation: there is more to growth than just surviving. Oncogene 2005, 24, 7435.

80. Engelman, J.A.; Luo, J.; Cantley, L.C. The evolution of phosphatidylinositol 3-kinases as regulators of growth and metabolism. Nature Reviews Genetics 2006, 7, 606.

81. Mînea, C.P.; Sano, H.; Kane, S.; Sano, E.; Fukuda, M.; Peränen, J.; Lane, W.S.; Lienhard, G.E. AS160, the Akt substrate regulating GLUT4 translocation, has a functional Rab GTPase-activating protein domain. Biochemical Journal2005, 391, 87-93.

82. Barthel, A.; Okino, S.T.; Liao, J.; Nakatani, K.; Li, J.; Whitlock, J.P.; Roth, R.A. Regulation of GLUT1 gene transcription by the serine/threonine kinase Akt1. Journal of Biological Chemistry 1999, 274, 20281-20286.

83. Jensen, P.J.; Gunter, L.B.; Carayannopoulos, M.O. Akt2 modulates glucose availability and downstream apoptotic pathways during development. The Journal of biological chemistry 2010, 285, 17673-17680, doi:10.1074/jbc.M109.079343.

84. Wieman, H.L.; Wofford, J.A.; Rathmell, J.C. Cytokine stimulation promotes glucose uptake via phosphatidylinositol-3 kinase/Akt regulation of Glut1 activity and trafficking. Molecular biology of the cell 2007, 18, 1437-1446.

85. Ben-Sahra, I.; Howell, J.J.; Asara, J.M.; Manning, B.D. Stimulation of de novo pyrimidine synthesis by growth signaling through mTOR and S6K1. Science 2013, 339, 1323-1328.

86. Nakashima, A.; Kawanishi, I.; Eguchi, S.; Yu, E.H.; Eguchi, S.; Oshiro, N.; Yoshino, K.-i.; Kikkawa, U.; Yonezawa, K. Association of CAD, a multifunctional protein involved in pyrimidine synthesis, with $\mathrm{mLST}$, a component of the mTOR complexes. Journal of biomedical science 2013, 20, 24.

87. Bakan, I.; Laplante, M. Connecting mTORC1 signaling to SREBP-1 activation. Current opinion in lipidology 2012, 23, 226-234.

88. Jeon, T.-I.; Osborne, T.F. SREBPs: metabolic integrators in physiology and metabolism. Trends in Endocrinology \& Metabolism 2012, 23, 65-72.

89. Guo, D.; Hlavin Bell, E.; Mischel, P.; Chakravarti, A. Targeting SREBP-1-driven lipid metabolism to treat cancer. Current pharmaceutical design 2014, 20, 2619-2626.

90. Berwick, D.C.; Hers, I.; Heesom, K.J.; Moule, S.K.; Tavaré, J.M. The identification of ATP-citrate lyase as a protein kinase B (Akt) substrate in primary adipocytes. Journal of Biological Chemistry 2002, 277, 33895-33900.

91. Edinger, A.L.; Thompson, C.B. Akt maintains cell size and survival by increasing mTOR-dependent nutrient uptake. Molecular biology of the cel/2002, 13, 2276-2288.

92. Ying, H.; Kimmelman, A.C.; Lyssiotis, C.A.; Hua, S.; Chu, G.C.; Fletcher-Sananikone, E.; Locasale, J.W.; Son, J.; Zhang, H.; Coloff, J.L. Oncogenic Kras maintains pancreatic tumors through regulation of anabolic glucose metabolism. Cel/2012, 149, 656-670.

93. Miller, D.M.; Thomas, S.D.; Islam, A.; Muench, D.; Sedoris, K. c-Myc and cancer metabolism. AACR: 2012.

94. Dang, C.V. MYC, metabolism, cell growth, and tumorigenesis. Cold Spring Harbor perspectives in medicine 2013, 3, a014217. 
95. Vander Heiden, M.G.; Cantley, L.C.; Thompson, C.B. Understanding the Warburg effect: the metabolic requirements of cell proliferation. science 2009, 324, 1029-1033.

96. Sever, R.; Brugge, J.S. Signal transduction in cancer. Cold Spring Harb Perspect Med 2015, 5, doi:10.1101/cshperspect.a006098.

97. Luo, W.; Hu, H.; Chang, R.; Zhong, J.; Knabel, M.; O'Meally, R.; Cole, R.N.; Pandey, A.; Semenza, G.L. Pyruvate kinase M2 is a PHD3-stimulated coactivator for hypoxia-inducible factor 1. Cel/2011, 145, 732-744.

98. Gao, X.; Wang, H.; Yang, J.J.; Liu, X.; Liu, Z.-R. Pyruvate kinase M2 regulates gene transcription by acting as a protein kinase. Molecular cel/2012, 45, 598-609.

99. Suzuki, S.; Tanaka, T.; Poyurovsky, M.V.; Nagano, H.; Mayama, T.; Ohkubo, S.; Lokshin, M.; Hosokawa, H.; Nakayama, T.; Suzuki, Y. Phosphate-activated glutaminase (GLS2), a p53-inducible regulator of glutamine metabolism and reactive oxygen species. Proceedings of the National Academy of Sciences 2010, 107, 7461-7466.

100. Kubatka, P.; Zihlavnikova, K.; Kajo, K.; Péc, M.; Stollárová, N.; Bojková, B.; Kassayová, M.; Orendas, P. Antineoplastic effects of simvastatin in experimental breast cancer. Klin Onko/2011, 24, 41-45.

101. Vicente-Manzanares, M.; Horwitz, A.R. Cell migration: an overview. In Cell migration, Springer: 2011; pp. $1-24$.

102. Devreotes, P.; Horwitz, A.R. Signaling networks that regulate cell migration. Cold Spring Harbor perspectives in biology 2015, 7, a005959.

103. Chin, Y.R.; Toker, A. Akt isoform-specific signaling in breast cancer: uncovering an anti-migratory role for palladin. Cell adhesion \& migration 2011, 5, 211-214.

104. Birchmeier, W.; Birchmeier, C. Epithelial-mesenchymal transitions in development and tumor progression. In Epithelial-Mesenchymal Interactions in Cancer, Springer: 1995; pp. 1-15.

105. Solimando, A.; Brandl, A.; Mattenheimer, K.; Graf, C.; Ritz, M.; Ruckdeschel, A.; Stühmer, T.; Mokhtari, Z.; Rudelius, M.; Dotterweich, J. JAM-A as a prognostic factor and new therapeutic target in multiple myeloma. Leukemia 2018, 32, 736-743.

106. Larue, L.; Bellacosa, A. Epithelial-mesenchymal transition in development and cancer: role of phosphatidylinositol 3' kinase/AKT pathways. Oncogene 2005, 24, 7443.

107. Doble, B.W.; Woodgett, J.R. Role of glycogen synthase kinase-3 in cell fate and epithelial-mesenchymal transitions. Cells Tissues Organs 2007, 185, 73-84.

108. Hussey, G.S.; Chaudhury, A.; Dawson, A.E.; Lindner, D.J.; Knudsen, C.R.; Wilce, M.C.; Merrick, W.C.; Howe, P.H. Identification of an mRNP complex regulating tumorigenesis at the translational elongation step. Molecular cel/ 2011, 41, 419-431.

109. Elsum, I.A.; Martin, C.; Humbert, P.O. Scribble regulates an EMT polarity pathway through modulation of MAPK-ERK signaling to mediate junction formation. J Cell Sci2013, 126, 3990-3999.

110. Nagasaka, K.; Seiki, T.; Yamashita, A.; Massimi, P.; Subbaiah, V.K.; Thomas, M.; Kranjec, C.; Kawana, K.; Nakagawa, S.; Yano, T. A novel interaction between hScrib and PP1 $\gamma$ downregulates ERK signaling and suppresses oncogene-induced cell transformation. PloS one 2013, 8, e53752.

111. Dow, L.; Elsum, I.; King, C.; Kinross, K.; Richardson, H.; Humbert, P. Loss of human Scribble cooperates with $\mathrm{H}$-Ras to promote cell invasion through deregulation of MAPK signalling. Oncogene 2008, 27, 5988.

112. Shaikh, S.; Collier, D.A.; Sham, P.C.; Ball, D.; Aitchison, K.; Vallada, H.; Kerwin, R.; Smith, I.; Gill, M. Allelic association between a Ser-9-Gly polymorphism in the dopamine D3 receptor gene and schizophrenia. Human genetics 1996, 97, 714-719.

113. Wu, M.; Pastor-Pareja, J.C.; Xu, T. Interaction between Ras V12 and scribbled clones induces tumour growth and invasion. Nature 2010, 463, 545. 
114. Iden, S.; van Riel, W.E.; Schäfer, R.; Song, J.-Y.; Hirose, T.; Ohno, S.; Collard, J.G. Tumor type-dependent function of the par3 polarity protein in skin tumorigenesis. Cancer ce//2012, 22, 389-403.

115. McCaffrey, L.M.; Montalbano, J.; Mihai, C.; Macara, I.G. Loss of the Par3 polarity protein promotes breast tumorigenesis and metastasis. Cancer cel/2012, 22, 601-614.

116. Xue, B.; Krishnamurthy, K.; Allred, D.C.; Muthuswamy, S.K. Loss of Par3 promotes breast cancer metastasis by compromising cell-cell cohesion. Nature cell biology 2013, 15, 189.

117. Siahmansouri, H.; Somi, M.H.; Babaloo, Z.; Baradaran, B.; Jadidi-Niaragh, F.; Atyabi, F.; Mohammadi, H.; Ahmadi, M.; Yousefi, M.J.J.o.P.; Pharmacology. Effects of HMGA 2 si RNA and doxorubicin dual delivery by chitosan nanoparticles on cytotoxicity and gene expression of HT-29 colorectal cancer cell line. 2016, 68, 1119-1130.

118. Karar, J.; Maity, A. PI3K/AKT/mTOR pathway in angiogenesis. Frontiers in molecular neuroscience 2011, 4, 51.

119. Nusse, R. Wnt signaling. Cold Spring Harbor Perspectives in Biology 2012, 4, a011163.

120. Kopan, R. Notch signaling. Cold Spring Harbor perspectives in biology 2012, 4, a011213.

121. Mazzone, M.; Selfors, L.M.; Albeck, J.; Overholtzer, M.; Sale, S.; Carroll, D.L.; Pandya, D.; Lu, Y.; Mills, G.B.; Aster, J.C. Dose-dependent induction of distinct phenotypic responses to Notch pathway activation in mammary epithelial cells. Proceedings of the National Academy of Sciences 2010, 107, 5012-5017.

122. Ingham, P.W. Hedgehog signaling. Cold Spring Harbor perspectives in biology 2012, 4, a011221.

123. Donnem, T.; Andersen, S.; Al-Shibli, K.; Al-Saad, S.; Busund, L.T.; Bremnes, R.M. Prognostic impact of Notch ligands and receptors in nonsmall cell lung cancer: coexpression of Notch-1 and vascular endothelial growth factor-A predicts poor survival. Cancer 2010, 116, 5676-5685.

124. Thiery, J.P. Epithelial-mesenchymal transitions in tumour progression. Nature Reviews Cancer 2002, 2, 442.

125. Keely, P.J. Mechanisms by which the extracellular matrix and integrin signaling act to regulate the switch between tumor suppression and tumor promotion. Journal of mammary gland biology and neoplasia 2011, $16,205$.

126. Bolós, V.; Gasent, J.M.; Lopez-Tarruella, S.; Grande, E. The dual kinase complex FAK-Src as a promising therapeutic target in cancer. OncoTargets and therapy 2010, 3, 83.

127. Zhao, X.; Guan, J.-L. Focal adhesion kinase and its signaling pathways in cell migration and angiogenesis. Advanced drug delivery reviews 2011, 63, 610-615.

128. Sun, C.-C.; Qu, X.-J.; Gao, Z.-H. Integrins: players in cancer progression and targets in cancer therapy. Anti-cancer drugs 2014, 25, 1107-1121.

129. Cantor, D.; Cheruku, H.; Nice, E.; Baker, M. Integrin $\alpha v \beta 6$ sets the stage for colorectal cancer metastasis. Cancer and Metastasis Reviews 2015, 34, 715-734.

130. Östman, A.; Augsten, M. Cancer-associated fibroblasts and tumor growth-bystanders turning into key players. Current opinion in genetics \& development 2009, 19,67-73.

131. Pietras, K.; Östman, A. Hallmarks of cancer: interactions with the tumor stroma. Experimental cell research 2010, 316, 1324-1331.

132. Eke, I.; Cordes, N. Focal adhesion signaling and therapy resistance in cancer. In Proceedings of Seminars in cancer biology; pp. 65-75.

133. Liu, T.; Zhou, L.; Li, D.; Andl, T.; Zhang, Y.J.F.i.c.; biology, d. Cancer-associated fibroblasts build and secure the tumor microenvironment. 2019, 7.

134. Porcelli, L.; lacobazzi, R.M.; Di Fonte, R.; Serratì, S.; Intini, A.; Solimando, A.G.; Brunetti, O.; Calabrese, A.; Leonetti, F.; Azzariti, A.J.C. CAFs and TGF- $\beta$ signaling activation by mast cells contribute to resistance to gemcitabine/nabpaclitaxel in pancreatic cancer. 2019, 11, 330. 
135. Bhowmick, N.A.; Neilson, E.G.; Moses, H.L. Stromal fibroblasts in cancer initiation and progression. Nature 2004, 432, 332-337, doi:10.1038/nature03096.

136. Raffaghello, L.; Vacca, A.; Pistoia, V.; Ribatti, D.J.O. Cancer associated fibroblasts in hematological malignancies. 2015, 6, 2589.

137. Frassanito, M.A.; Desantis, V.; Di Marzo, L.; Craparotta, I.; Beltrame, L.; Marchini, S.; Annese, T.; Visino, F.; Arciuli, M.; Saltarella, I.J.T.J.o.p. Bone marrow fibroblasts overexpress miR-27b and miR-214 in step with multiple myeloma progression, dependent on tumour cell-derived exosomes. 2019, 247, 241-253.

138. Arora, P.D.; Wang, Y.; Janmey, P.A.; Bresnick, A.; Yin, H.L.; McCulloch, C.A. Gelsolin and non-muscle myosin IIA interact to mediate calcium-regulated collagen phagocytosis. Journal of Biological Chemistry 2011, 286, 34184-34198.

139. Rodriguez, A.; Karen, J.; Gardner, H.; Gerdin, B.; Rubin, K.; Sundberg, C. Integrin $\alpha 1 \beta 1$ is involved in the differentiation into myofibroblasts in adult reactive tissues in vivo. Journal of cellular and molecular medicine 2009, 13, 3449-3462.

140. $\mathrm{Wu}$, J.E.; Santoro, S.A. Complex patterns of expression suggest extensive roles for the $\alpha 2 \beta 1$ integrin in murine development. Developmental dynamics 1994, 199, 292-314.

141. Pozzi, A.; Moberg, P.E.; Miles, L.A.; Wagner, S.; Soloway, P.; Gardner, H.A. Elevated matrix metalloprotease and angiostatin levels in integrin $\alpha 1$ knockout mice cause reduced tumor vascularization. Proceedings of the National Academy of Sciences 2000, 97, 2202-2207.

142. Hemler, M.E.; Jacobson, J.G.; Strominger, J.L. Biochemical characterization of VLA-1 and VLA-2. Cell surface heterodimers on activated T cells. Journal of Biological Chemistry 1985, 260, 15246-15252.

143. Schulz, J.-N.; Zeltz, C.; Sørensen, I.W.; Barczyk, M.; Carracedo, S.; Hallinger, R.; Niehoff, A.; Eckes, B.; Gullberg, D. Reduced granulation tissue and wound strength in the absence of $\alpha 11 \beta 1$ integrin. Journal of Investigative Dermatology 2015, 135, 1435-1444.

144. Navab, R.; Strumpf, D.; To, C.; Pasko, E.; Kim, K.; Park, C.; Hai, J.; Liu, J.; Jonkman, J.; Barczyk, M. Integrin $\alpha 11 \beta 1$ regulates cancer stromal stiffness and promotes tumorigenicity and metastasis in non-small cell lung cancer. Oncogene 2016, 35, 1899.

145. Westcott, J.M.; Prechtl, A.M.; Maine, E.A.; Dang, T.T.; Esparza, M.A.; Sun, H.; Zhou, Y.; Xie, Y.; Pearson, G.W. An epigenetically distinct breast cancer cell subpopulation promotes collective invasion. The Journal of clinical investigation 2015, 125, 1927-1943.

146. Kalluri, R.; Zeisberg, M. Fibroblasts in cancer. Nature Reviews Cancer 2006, 6, 392.

147. Rybinski, B.; Franco-Barraza, J.; Cukierman, E. The wound healing, chronic fibrosis, and cancer progression triad. Physiological genomics 2014, 46, 223-244.

148. Shinde, A.V.; Bystroff, C.; Wang, C.; Vogelezang, M.G.; Vincent, P.A.; Hynes, R.O.; Van De Water, L. Identification of the peptide sequences within the EIIIA (EDA) segment of fibronectin that mediate integrin $\alpha 9 \beta 1$-dependent cellular activities. Journal of Biological Chemistry 2008, 283, 2858-2870.

149. Serini, G.; Bochaton-Piallat, M.-L.; Ropraz, P.; Geinoz, A.; Borsi, L.; Zardi, L.; Gabbiani, G. The fibronectin domain ED-A is crucial for myofibroblastic phenotype induction by transforming growth factor- $\beta 1$. The Journal of cell biology 1998, 142, 873-881.

150. Hinz, B. Formation and function of the myofibroblast during tissue repair. Journal of Investigative Dermatology 2007, 127, 526-537.

151. Pietras, K.; Pahler, J.; Bergers, G.; Hanahan, D. Functions of paracrine PDGF signaling in the proangiogenic tumor stroma revealed by pharmacological targeting. PLoS medicine 2008, 5, e19.

152. Klingberg, F.; Chow, M.L.; Koehler, A.; Boo, S.; Buscemi, L.; Quinn, T.M.; Costell, M.; Alman, B.A.; Genot, E.; Hinz, B. Prestress in the extracellular matrix sensitizes latent TGF- $\beta 1$ for activation. J Cell Bio/2014, 207, 283-297. 
153. Baker, A.; Bird, D.; Lang, G.; Cox, T.R.; Erler, J. Lysyl oxidase enzymatic function increases stiffness to drive colorectal cancer progression through FAK. Oncogene 2013, 32, 1863.

154. Hooper, S.; Gaggioli, C.; Sahai, E. A chemical biology screen reveals a role for Rab21-mediated control of actomyosin contractility in fibroblast-driven cancer invasion. British journal of cancer 2010, 102, 392.

155. Gaggioli, C.; Hooper, S.; Hidalgo-Carcedo, C.; Grosse, R.; Marshall, J.F.; Harrington, K.; Sahai, E. Fibroblast-led collective invasion of carcinoma cells with differing roles for RhoGTPases in leading and following cells. Nature cell biology 2007, 9, 1392.

156. Medjkane, S.; Perez-Sanchez, C.; Gaggioli, C.; Sahai, E.; Treisman, R. Myocardin-related transcription factors and SRF are required for cytoskeletal dynamics and experimental metastasis. Nature cell biology 2009, 11, 257.

157. Sanz-Moreno, V.; Gaggioli, C.; Yeo, M.; Albrengues, J.; Wallberg, F.; Viros, A.; Hooper, S.; Mitter, R.; Féral, C.C.; Cook, M. ROCK and JAK1 signaling cooperate to control actomyosin contractility in tumor cells and stroma. Cancer cel/2011, 20, 229-245.

158. Fu, H.-L.; Valiathan, R.R.; Arkwright, R.; Sohail, A.; Mihai, C.; Kumarasiri, M.; Mahasenan, K.V.; Mobashery, S.; Huang, P.; Agarwal, G. Discoidin domain receptors: unique receptor tyrosine kinases in collagen-mediated signaling. Journal of Biological Chemistry 2013, 288, 7430-7437.

159. Leitinger, B. Discoidin domain receptor functions in physiological and pathological conditions. In International review of cell and molecular biology, Elsevier: 2014; Vol. 310, pp. 39-87.

160. Carafoli, F.; Mayer, M.C.; Shiraishi, K.; Pecheva, M.A.; Chan, L.Y.; Nan, R.; Leitinger, B.; Hohenester, E. Structure of the discoidin domain receptor 1 extracellular region bound to an inhibitory Fab fragment reveals features important for signaling. Structure 2012, 20,688-697.

161. Valiathan, R.R.; Marco, M.; Leitinger, B.; Kleer, C.G.; Fridman, R. Discoidin domain receptor tyrosine kinases: new players in cancer progression. Cancer and Metastasis Reviews 2012, 31, 295-321.

162. Borza, C.M.; Pozzi, A. Discoidin domain receptors in disease. Matrix Biology 2014, 34, 185-192.

163. Hidalgo-Carcedo, C.; Hooper, S.; Chaudhry, S.I.; Williamson, P.; Harrington, K.; Leitinger, B.; Sahai, E. Collective cell migration requires suppression of actomyosin at cell-cell contacts mediated by DDR 1 and the cell polarity regulators Par3 and Par6. Nature cell biology 2011, 13, 49.

164. Kim, H.-G.; Hwang, S.-Y.; Aaronson, S.A.; Mandinova, A.; Lee, S.W. DDR1 receptor tyrosine kinase promotes prosurvival pathway through Notch1 activation. Journal of Biological Chemistry 2011, 286, 17672-17681.

165. Zhang, K.; Corsa, C.A.; Ponik, S.M.; Prior, J.L.; Piwnica-Worms, D.; Eliceiri, K.W.; Keely, P.J.; Longmore, G.D. The collagen receptor discoidin domain receptor 2 stabilizes SNAIL1 to facilitate breast cancer metastasis. Nature cell biology 2013, 15, 677.

166. Hammerman, P.S.; Sos, M.L.; Ramos, A.H.; Xu, C.; Dutt, A.; Zhou, W.; Brace, L.E.; Woods, B.A.; Lin, W.; Zhang, J. Mutations in the DDR2 kinase gene identify a novel therapeutic target in squamous cell lung cancer. Cancer discovery 2011, 1, 78-89.

167. Xu, D.; Esko, J.D. Demystifying heparan sulfate-protein interactions. Annual review of biochemistry 2014, 83, 129-157.

168. Milner, C.; Tongsoongnoen, W.; Rugg, M.; Day, A. The molecular basis of inter- $\alpha$-inhibitor heavy chain transfer on to hyaluronan. Portland Press Limited: 2007.

169. Nikitovic, D.; Tzardi, M.; Berdiaki, A.; Tsatsakis, A.; Tzanakakis, G.N. Cancer microenvironment and inflammation: role of hyaluronan. Frontiers in immunology 2015, 6, 169.

170. Filmus, J.; Capurro, M.; Rast, J. Glypicans. Genome biology 2008, 9, 224.

171. Xian, X.; Gopal, S.; Couchman, J.R. Syndecans as receptors and organizers of the extracellular matrix. Cell and tissue research 2010, 339, 31. 
172. Lowy, C.M.; Oskarsson, T. Tenascin C in metastasis: A view from the invasive front. Cell adhesion \& migration 2015, 9, 112-124.

173. Gurbuz, l.; Chiquet-Ehrismann, R. CCN4/WISP1 (WNT1 inducible signaling pathway protein 1): a focus on its role in cancer. The international journal of biochemistry \& cell biology 2015, 62, 142-146.

174. Price, M.A.; Colvin Wanshura, L.E.; Yang, J.; Carlson, J.; Xiang, B.; Li, G.; Ferrone, S.; Dudek, A.Z.; Turley, E.A.; McCarthy, J.B. CSPG4, a potential therapeutic target, facilitates malignant progression of melanoma. Pigment cell \& melanoma research 2011, 24, 1148-1157.

175. Cattaruzza, S.; Perris, R. Proteoglycan control of cell movement during wound healing and cancer spreading. Matrix Biology 2005, 24, 400-417.

176. Orian-Rousseau, V. CD44, a therapeutic target for metastasising tumours. European journal of cancer 2010, 46, 1271-1277.

177. Bourguignon, L.Y.; Bikle, D. Selective hyaluronan-CD44 signaling promotes miRNA-21 expression and interacts with vitamin D function during cutaneous squamous cell carcinomas progression following UV irradiation. Frontiers in immunology 2015, 6, 224.

178. Misra, S.; Hascall, V.C.; Markwald, R.R.; Ghatak, S. Interactions between hyaluronan and its receptors (CD44, RHAMM) regulate the activities of inflammation and cancer. Frontiers in immunology 2015, 6, 201.

179. Ajani, J.A.; Song, S.; Hochster, H.S.; Steinberg, I.B. Cancer stem cells: the promise and the potential. In Proceedings of Seminars in oncology; pp. S3-S17.

180. Sanderson, R.; Couchman, J. Targeting syndecan shedding in cancer. Extracellular Matrix: Pathobiology and Signaling (Karamanos NK, ed.) 2012, 802-812.

181. Yoneda, A.; Lendorf, M.E.; Couchman, J.R.; Multhaupt, H.A. Breast and ovarian cancers: a survey and possible roles for the cell surface heparan sulfate proteoglycans. Journal of Histochemistry \& Cytochemistry 2012, 60, 9-21.

182. Ramani, V.C.; Purushothaman, A.; Stewart, M.D.; Thompson, C.A.; Vlodavsky, I.; Au, J.L.S.; Sanderson, R.D. The heparanase/syndecan-1 axis in cancer: mechanisms and therapies. The FEBS journa/2013, 280, 2294-2306.

183. Alexander, C.M.; Reichsman, F.; Hinkes, M.T.; Lincecum, J.; Becker, K.A.; Cumberledge, S.; Bernfield, M. Syndecan-1 is required for Wnt-1-induced mammary tumorigenesis in mice. Nature genetics 2000, $25,329$.

184. Lee, P.C.; Salyapongse, A.N.; Bragdon, G.A.; Shears, L.L.; Watkins, S.C.; Edington, H.D.; Billiar, T.R. Impaired wound healing and angiogenesis in eNOS-deficient mice. Am J Physiol 1999, 277, H1600-1608, doi:10.1152/ajpheart.1999.277.4.h1600.

185. Jridi, I.; Catacchio, I.; Majdoub, H.; Shahbazzadeh, D.; El Ayeb, M.; Frassanito, M.A.; Solimando, A.G.; Ribatti, D.; Vacca, A.; Borchani, L. The small subunit of Hemilipin2, a new heterodimeric phospholipase A2 from Hemiscorpius lepturus scorpion venom, mediates the antiangiogenic effect of the whole protein. Toxicon 2017, 126, 38-46, doi:10.1016/j.toxicon.2016.12.001.

186. Simone, V.; Brunetti, O.; Lupo, L.; Testini, M.; Maiorano, E.; Simone, M.; Longo, V.; Rolfo, C.; Peeters, M.; Scarpa, A. Targeting angiogenesis in biliary tract cancers: An open option. International journal of molecular sciences 2017, 18, 418.

187. Longo, V.; Brunetti, O.; Gnoni, A.; Cascinu, S.; Gasparini, G.; Lorusso, V.; Ribatti, D.; Silvestris, N. Angiogenesis in pancreatic ductal adenocarcinoma: a controversial issue. Oncotarget 2016, 7, 58649.

188. Lamanuzzi, A.; Saltarella, I.; Desantis, V.; Frassanito, M.A.; Leone, P.; Racanelli, V.; Nico, B.; Ribatti, D.; Ditonno, P.; Prete, M., et al. Inhibition of mTOR complex 2 restrains tumor angiogenesis in multiple myeloma. Oncotarget 2018, 9, 20563-20577, doi:10.18632/oncotarget.25003.

189. Farhan, M.A.; Carmine-Simmen, K.; Lewis, J.D.; Moore, R.B.; Murray, A.G. Endothelial Cell mTOR Complex-2 Regulates Sprouting Angiogenesis. PloS one 2015, 10, e0135245, doi:10.1371/journal.pone.0135245. 
190. Li, S.; Xu, B.; An, Z.; Wang, Z.; Li, Y.; Wei, L.; Wei, D. Evolutionary analysis of TSP-1 gene in Plateau zokor (MyospalaxBaileyi) and its expression pattern under hypoxia. Cellular and molecular biology (Noisy-le-Grand, France) 2019, 65, 48-57.

191. Zaslavsky, A.; Chen, C.; Grillo, J.; Baek, K.H.; Holmgren, L.; Yoon, S.S.; Folkman, J.; Ryeom, S. Regional control of tumor growth. Molecular cancer research : MCR 2010, 8, 1198-1206, doi:10.1158/1541-7786.Mcr-10-0047.

192. Green, D.R.; Llambi, F. Cell death signaling. Cold Spring Harbor perspectives in biology 2015, 7, a006080.

193. Qian, B.-Z.; Pollard, J.W.J.C. Macrophage diversity enhances tumor progression and metastasis. 2010, 141, 39-51.

194. Zumsteg, A.; Christofori, G.J.C.o.i.o. Corrupt policemen: inflammatory cells promote tumor angiogenesis. 2009, 21, 60-70.

195. Murdoch, C.; Muthana, M.; Coffelt, S.B.; Lewis, C.E.J.N.r.c. The role of myeloid cells in the promotion of tumour angiogenesis. 2008, 8, 618-631.

196. Longo, V.; Brunetti, O.; Gnoni, A.; Cascinu, S.; Gasparini, G.; Lorusso, V.; Ribatti, D.; Silvestris, N. Angiogenesis in pancreatic ductal adenocarcinoma: A controversial issue. Oncotarget 2016, 7, 58649-58658, doi:10.18632/oncotarget.10765.

197. Leone, P.; Buonavoglia, A.; Fasano, R.; Solimando, A.G.; De Re, V.; Cicco, S.; Vacca, A.; Racanelli, V. Insights into the Regulation of Tumor Angiogenesis by Micro-RNAs. Journal of clinical medicine 2019, 8, doi:10.3390/jcm8122030.

198. Ferrara, N.J.C.; reviews, g.f. Pathways mediating VEGF-independent tumor angiogenesis. 2010, 21, 21-26.

199. Patenaude, A.; Parker, J.; Karsan, A.J.M.r. Involvement of endothelial progenitor cells in tumor vascularization. 2010, 79, 217-223.

200. Ziegelhoeffer, T.; Fernandez, B.; Kostin, S.; Heil, M.; Voswinckel, R.; Helisch, A.; Schaper, W.J.C.r. Bone marrow-derived cells do not incorporate into the adult growing vasculature. 2004, 94, 230-238.

201. Yoder, M.C.; Ingram, D.A.J.C.o.i.h. Endothelial progenitor cell: ongoing controversy for defining these cells and their role in neoangiogenesis in the murine system. 2009, 16, 269-273.

202. Leone, P.; Di Lernia, G.; Solimando, A.G.; Cicco, S.; Saltarella, I.; Lamanuzzi, A.; Ria, R.; Frassanito, M.A.; Ponzoni, M.; Ditonno, P.J.O. Bone marrow endothelial cells sustain a tumor-specific CD8+ T cell subset with suppressive function in myeloma patients. 2019, 8, e1486949.

203. Albini, A.; Bruno, A.; Noonan, D.M.; Mortara, L.J.F.i.i. Contribution to tumor angiogenesis from innate immune cells within the tumor microenvironment: implications for immunotherapy. 2018, 9, 527.

204. Grivennikov, S.I.; Wang, K.; Mucida, D.; Stewart, C.A.; Schnabl, B.; Jauch, D.; Taniguchi, K.; Yu, G.-Y.; Österreicher, C.H.; Hung, K.E. Adenoma-linked barrier defects and microbial products drive IL-23/IL-17-mediated tumour growth. Nature 2012, 491, 254.

205. Newton, K.; Dixit, V.M. Signaling in innate immunity and inflammation. Cold Spring Harbor perspectives in biology 2012, 4, a006049.

206. Karin, M. NF-кB as a critical link between inflammation and cancer. Cold Spring Harbor perspectives in biology 2009, 1, a000141.

207. Misra, B.B.; Langefeld, C.; Olivier, M.; Cox, L.A. Integrated omics: tools, advances and future approaches. Journal of molecular endocrinology 2019, 62, R21-R45.

208. Solimando, A.G.; Da Vià, M.C.; Cicco, S.; Leone, P.; Di Lernia, G.; Giannico, D.; Desantis, V.; Frassanito, M.A.; Morizio, A.; Delgado Tascon, J., et al. High-Risk Multiple Myeloma: Integrated Clinical and Omics Approach Dissects the Neoplastic Clone and the Tumor Microenvironment. Journal of clinical medicine 2019, 8, doi:10.3390/jcm8070997. 
209. Bardini, R.; Politano, G.; Benso, A.; Di Carlo, S. Multi-level and hybrid modelling approaches for systems biology. Computational and structural biotechnology journal 2017, 15, 396-402, doi:10.1016/j.csbj.2017.07.005.

210. Korsunsky, I.; McGovern, K.; LaGatta, T.; Olde Loohuis, L.; Grosso-Applewhite, T.; Griffeth, N.; Mishra, B. Systems Biology of Cancer: A Challenging Expedition for Clinical and Quantitative Biologists. Frontiers in Bioengineering and Biotechnology 2014, 2, doi:10.3389/fbioe.2014.00027.

211. Kuenzi, B.M.; Ideker, T. A census of pathway maps in cancer systems biology. Nature Reviews Cancer 2020, 10.1038/s41568-020-0240-7, doi:10.1038/s41568-020-0240-7.

212. Sambath, J.; Patel, K.; Limaye, S.; Kumar, P. Single-Cell Multiomics: Dissecting Cancer. In Statistical Modelling and Machine Learning Principles for Bioinformatics Techniques, Tools, and Applications, Srinivasa, K.G., Siddesh, G.M., Manisekhar, S.R., Eds. Springer Singapore: Singapore, 2020; 10.1007/978-981-15-2445-5_14pp. 289-317.

213. Cho, S.Y.J.G.; informatics. Identification of ERBB pathway-activated cells in triple-negative breast cancer. 2019, 17.

214. Lim, B.; Lin, Y.; Navin, N.J.C.C. Advancing Cancer Research and Medicine with Single-Cell Genomics. 2020, 37, 456-470.

215. Ho, Y.-J.; Anaparthy, N.; Molik, D.; Mathew, G.; Aicher, T.; Patel, A.; Hicks, J.; Hammell, M.G.J.G.r. Single-cell RNA-seq analysis identifies markers of resistance to targeted BRAF inhibitors in melanoma cell populations. 2018, 28, 1353-1363.

216. Rambow, F.; Rogiers, A.; Marin-Bejar, O.; Aibar, S.; Femel, J.; Dewaele, M.; Karras, P.; Brown, D.; Chang, Y.H.; Debiec-Rychter, M., et al. Toward Minimal Residual Disease-Directed Therapy in Melanoma. Cell 2018, 174, 843-855.e819, doi:https://doi.org/10.1016/j.cell.2018.06.025.

217. Miyamoto, D.T.; Zheng, Y.; Wittner, B.S.; Lee, R.J.; Zhu, H.; Broderick, K.T.; Desai, R.; Fox, D.B.; Brannigan, B.W.; Trautwein, J.J.S. RNA-Seq of single prostate CTCs implicates noncanonical Wnt signaling in antiandrogen resistance. 2015, 349, 1351-1356.

218. Keener, A.B.J.N.m. Single-cell sequencing edges into clinical trials. 2019, 25, 1322.

219. Wang, W.; Gao, D.; Wang, X.J.C.B.; Toxicology. Can single-cell RNA sequencing crack the mystery of cells? 2017, 34, 1-6. 